This item was submitted to Loughborough's Research Repository by the author.

Items in Figshare are protected by copyright, with all rights reserved, unless otherwise indicated.

\title{
Multi-body dynamics: historical evolution and application
}

PLEASE CITE THE PUBLISHED VERSION

PUBLISHER

Professional Engineering Publishing / @ IMECHE

VERSION

VoR (Version of Record)

LICENCE

CC BY-NC-ND 4.0

REPOSITORY RECORD

Rahnejat, Homer. 2019. "Multi-body Dynamics: Historical Evolution and Application”. figshare. https://hdl.handle.net/2134/4778. 
This item was submitted to Loughborough's Institutional Repository (https://dspace.lboro.ac.uk/) by the author and is made available under the following Creative Commons Licence conditions.

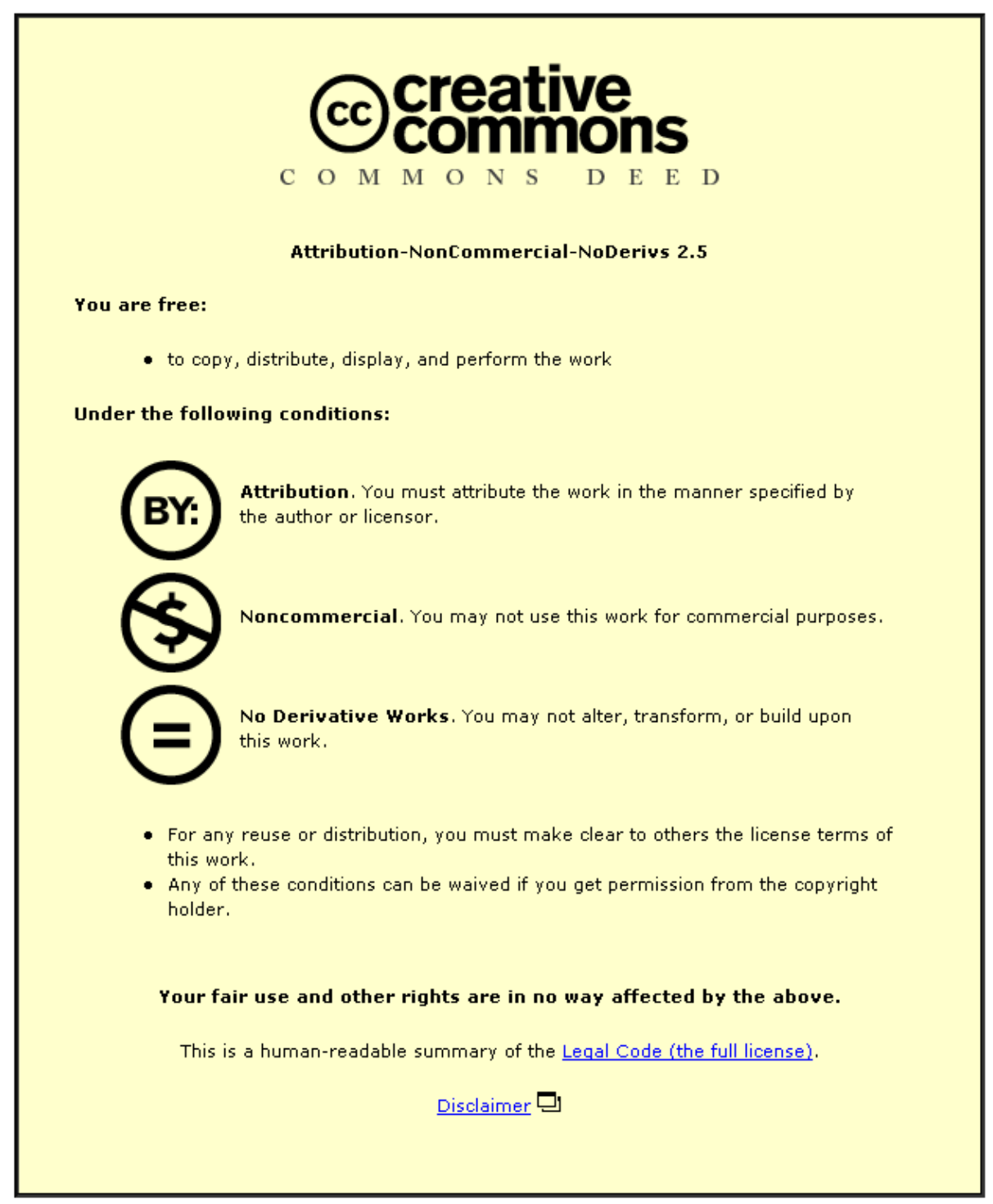

For the full text of this licence, please go to: http://creativecommons.org/licenses/by-nc-nd/2.5/ 


\title{
Multi-body dynamics: historical evolution and application
}

\author{
H Rahnejat \\ Department of Mechanical Engineering, University of Bradford, Bradford BD7 1DP, UK
}

\begin{abstract}
The historical developments in the discipline of engineering dynamics are briefly reviewed, with attention paid to the formulation and solution of the dynamic behaviour of multi-body systems. It is shown that the dynamic characteristics of practical multi-body systems are dependent upon the interactions of many physical phenomena that can induce, restrain or constrain motion of parts. The long process of understanding and formulating the physics of multi-body motions, in some cases with pioneering contributions centuries old, together with continual refinements in numerical techniques and enhanced computing power has resulted in the solution of quite complex and practical engineering problems. Linking the historical developments to the fundamental physical phenomena and their interactions, the paper presents solutions to two complex multi-body dynamic problems. The practical implications of the approach in design of these systems are highlighted.
\end{abstract}

Keywords: multi-body dynamics, vehicle handling, engine NVII, thin shell bearings

\author{
NOTATION \\ $A_{\mathrm{p}} \quad$ piston crown area \\ $c \quad$ clearance in the journal bearing \\ C constraints \\ d journal shell thickness \\ $e \quad$ journal eccentricity \\ $E \quad$ modulus of elasticity \\ $F_{\mathrm{f}} \quad$ piston friction force \\ $F_{j k} \quad k$ th harmonic of the $j$ th cylinder gas force \\ $h \quad$ lubricant film thickness \\ $h_{\mathrm{c}} \quad$ lower calorific value of the fuel mixture \\ $h_{\mathrm{t}} \quad$ instantaneous heat transfer coefficient \\ $i \quad$ part identification number \\ $j \quad$ cylinder identification number \\ $k \quad$ harmonic of four-stroke combustion frequency \\ $m \theta$ mass fraction of burnt fuel \\ $n \quad$ number of cylinders \\ $p \quad$ lubricant pressure \\ $P \quad$ combustion pressure \\ $Q \quad$ heat energy \\ $r \quad$ radius of the journal \\ $t$ time \\ $T_{\mathrm{g}} \quad$ gas temperature \\ $T_{\mathrm{W}} \quad$ cylinder wall temperature \\ $u$ speed of entraining motion \\ $u_{\mathrm{c}} \quad$ tangential speed of the crankshaft
}

The MS was received on 19 February 1999 and was accepted after revision for publication on 21 May 1999.

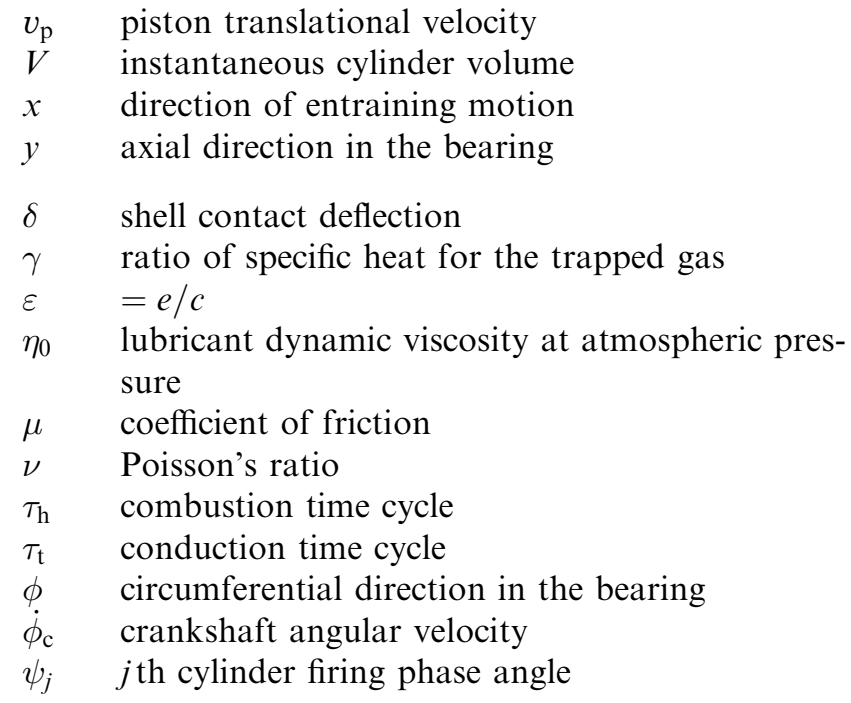

\section{INTRODUCTION}

Dynamics as a multifaceted phenomenon has its roots at the origin of creation. It was conceived with the inception of time at the 'big bang'. Since then it has affected everything and everyone in its many physical forms, from electromagnetic radiation to gravitation, from propulsion to combustion, to name but a few of its many facets.

Everything on earth, living or inanimate, has been affected by dynamic phenomena for nearly 4.6 billion years. Yet the physics of dynamic phenomena has 
probably only come to be observed in any meaningful sense in the past 10000 years, if one is to accept the currently acknowledged historical evidence pointing to the astrological interpretations in the ancient Inca's markings, the Stonehenge Circle, the Aztec buildings or the Pharaohs' Pyramids. The practical use of dynamics as a tool must have first taken place with the use of rolling logs for the transportation of heavy stone slabs to the construction sites and the hoisting of these with rudimentary pulleys. These early inventions, almost unwittingly using dynamic principles, must have occurred along with the use of wheels, which coupled with a cart, a horse and a driver, must represent the first multibody dynamic system. Therefore, instinctive observations, as distinct from a fundamental physical understanding of the environment, had clearly led to the harnessing of some facets of dynamic phenomena even in ancient times.

Dynamics as a discipline, as a science and as it is understood today has its roots rather coincidentally but aptly in the fundamental understanding of its origins, in the motions of heavenly bodies. This owes much to the observations of Galileo [1, 2] and Kepler [3, 4]. It would be hard to identify another who has had such a profound pioneering effect upon the advancement of a discipline of science as Galileo in the field of dynamics, coming in an age of superstition not science. His discovery of simple harmonic motion in the late sixteenth century forms the basis of modern dynamics. Interestingly, in 1592 he took the trouble of dropping balls from the top of the leaning Tower of Pisa to ascertain that the rate of fall is constant for all balls of different mass, thus unwittingly discovering the acceleration of free fall. This finding contradicted the widely held Aristotelian belief that speed of fall is proportional to weight. The experiment resulted in his dismissal from his position in the University of Pisa. He also favoured the astronomical Copernican treatise [5] by noting its concordance with the moon-induced tidal observations of Da Vinci. His alliance with Kepler and Brahe to repudiate the Ptolemaic theory of 'Earth-centred Universe' led to Kepler's laws of planetary motion and the foundation of physics of motion, but also to his impeachment by the ecclesiastical authorities in 1614.

If Galileo's free falling masses was an experiment of intent, more than a hundred years on a mere arguable accident with a falling apple led to the greatest scientific discovery of all time by Sir Isaac Newton. His Principia Mathematica [6] sets the laws and conditions of motion which have since formed the basis for the formulation of all dynamic problems. Newton was able to describe dynamics of particles and interplanetary interactions and movements with his three laws of motion. A century later the formulation for dynamics of constrained multibody systems was devised by Lagrange, outlined in his masterpiece Mécanique Analytique [7]. This ingenious contribution opened the way for formulation and solu- tion of complex and practical mechanisms, making Lagrange the father of multi-body dynamics as it is defined today. The formulation method is so robust and generic that it has not only withstood the test of time, but also has required no significant modification or advancement since its inception in 1788, a feat achieved by few contributions in the history of science. Additions to multi-body dynamics theory since then have been in the development of more efficient numerical solutions of what has rightly become known as Lagrangian dynamics, or in the inclusion of some practical features such as friction (by Coulomb), beam elasticity (by Euler [8]), contact compliance (by Hertz [9]) and lubrication (by Reynolds [10] and extended by Ertel and Grubin [11]). The inclusion of these additional features has paved the way for the analysis of complex and practical modern machines and mechanisms.

Only in the very recent past, with the advent of ever increasing computing power, has analysis of practical multi-body dynamic problems become possible. Four hundred years since Galileo and 200 years since the publication of Mécanique Analytique, using the same principles but with considerably improved matrix manipulation techniques (presented by Denavit and Hartenberg [12], and numerical integration methods for 'stiff' systems devised by Gear [13, 14], Petzold [15] and Ascher and Petzold [16], it is possible to analyse not only mechanisms as simple as the swinging chandelier, which roused the curiosity of Galileo, but also complex multibody systems. These include multicylinder automobile engines and full-vehicle ride and handling models. Both these models and their practical uses are described later in Sections 2 and 3.

The very first application of rigid body dynamics was described by Euler [8] in his masterly derivation of kinematic relations for a single gyro, followed by the dynamic equations of motion. A satisfactory solution for gyrodynamics took the better part of 200 years, until Gammel [17] presented his solution for a two-gimbal gyro in 1950, with which contribution multi-body dynamics as a practical engineering discipline was born. In practical gyrosystems a cardanic suspension must be considered which can lead to the attainment of singular positions in the initial analysis put forward by Gammel [17]. This problem was later remedied by Magnus [18] who considered the constraints in two-gimbal gyrodynamics. In fact the concept of constraint formulation for use in Lagrange's equation for constrained systems is the key for the numerical representation of multi-body systems in their practical assembly as well as for description of their functional assurance.

In rigid multi-bodies, $6 n$ unconstrained degrees of freedom exist for an assembly of $n$ parts which may be constrained by an $m$ number of holonomic constraints. The holonomic constraints arise from the existence of joints in the assembly of parts. They are represented as algebraic functions, with one or a number of them 
describing a practical joint. Therefore, a constrained rigid body mechanism has $6 n-m$ degrees of freedom. In practice, nothing is rigid and the elasticity of parts contributes to further coupled and uncoupled degrees of freedom in a multi-body system. The action of elastic members and indeed various sources of compliance was originally formulated by Euler in free body representation of reactions and is appropriately termed a restraint; the subtle distinction from a constraint is thus established.

The past 100 years have seen progressive improvements in solution methods and an increasing domain of application. The applications have included all aspects of machines, mechanisms and vehicle design analyses in their broadest sense. Early contributions at the turn of the century included motion evaluation in constrained planar mechanisms by Wittenbauer [19] which is considered as the forerunning work in the analysis of linkage mechanisms, and rigid body dynamics of human gait by Fischer [20]. However, the complexity of practical mechanisms, inefficient solvers and lack of computing power were largely responsible for the slow progress in multi-body dynamic analysis.

In 1956 Segel [21] studied the motion of a vehicle on a flat road and in response to wheel steer inputs. He was able to predict with some accuracy the behaviour of the vehicle in cornering with his linear model for lateral accelerations up to $0.3 \mathrm{~g}$. Segel's investigation coincided with the onset of mass car ownership and resulted in a greater interest in vehicle handling analysis through multi-body dynamics. The ever improving computational power added an impetus to this trend, culminating in the very first ride and handling analysis by McHenry [22] and the development of the highway vehicle object simulation model (HVOSM) in the United States. A flurry of activity in the field ensued in the early to mid-1970s, almost 200 years after the formulation of the Newton-Euler equations [8].

In 1977 Orlandea et al. [23] presented the first practical solution methodology for large rigid multi-body dynamic systems, based upon Lagrangian dynamics for constrained systems. Their work culminated in the development of ADAMS, an acronym for automatic dynamic analysis of mechanical systems, the spread and increasing use of which in industry has acted as the main driving force for many developments that have since taken place. Some notable contributions include symbolic manipulation of equations of motion for rigid multi-body models by Levinson [24] and Schiehlen and Kreuzer [25].

Vehicle ride and handling analysis has received the most attention and represents the largest growth area in the application of multi-body dynamics as described by Kortüm and Sharp [26], Kortüm and Schiehlen [27], Sharp [28, 29], Schiehlen and Schafer [30], Kübler and Schiehlen [31], Abe [32] and Evans [33, 34]. Most vehicle dynamic analyses deal with ride and handling issues as outlined in reference [26]. There has been a gradual trend towards the inclusion of flexible elements in the analysis of multi-body systems [35-40]. These include, for example, vehicle suspension analysis [40], active elements in suspension roll and vehicle yaw control [32] and consideration of fluid-structure interactions as in aerodynamic effects and fluid sloshing within the vehicle and their effects upon the roll-over characteristics of vehicles [41-45].

A growing area with considerable potential in industry is multi-body dynamic analysis of powertrain systems. Solutions for shaft and bearing systems have been gaining in complexity as the equations of motion, developed in Newton-Euler form, include contact dynamics of bearing supports. Solutions for five degrees of freedom motion verified against experimental findings have been reported by Aini et al. [46, 47]. The level of detail has included the modelling of bearing setting, preloading, interference fitting, out-of-balance assembly errors, elastodynamics of the shaft and manufacturing anomalies in rolling mating surfaces of rolling elements and raceways [48-50]. Lubricated contacts under a mixed regime of lubrication have also been included in the shaft and bearing and gear meshing multi-body models under dynamic conditions [51, 52].

In the vehicle refinement area, much attention has been paid in recent years to the analysis of powertrain systems for the reduction of noise and vibration. Such analyses comprise simultaneous solution for large displacement dynamics such as piston and connecting rod motions and infinitesimal elastic response of, for example, crankshaft pieces and support bearings. The spectrum of response is typically in the region 8 $5000 \mathrm{~Hz}$, stretching the numerical solvers to their limits. Zeischka et al. [53] highlight a multi-body elastodynamic model of the crankshaft and the engine block, making use of finite element models to represent the elastic behaviour of the various components. The hydrodynamic action of the supporting journal bearings was taken into account by impedance charts, providing the journal reactions as a function of the Sommerfeld number. The authors were able accurately to predict the vibration characteristics of four-stroke, four-cylinder, in-line internal combustion engines. A similar approach was undertaken by Katano et al. [54] for prediction of dynamic forces generated in an engine, inducing resonant conditions in the crankshaft system and studying durability of engine components under actual operating conditions. Lacy [55] has also carried out torsional vibration analysis of a four-cylinder gasoline engine, using a multi-body model. In his model the crankshaft nodes were connected to the main bearing housing by an oil-film module having a linear and rotary stiffness and damping. This model was initially reported by Kikuchi [56], with its rotary component simulating the generated friction torque in the crankshaft system. In Lacy's multibody model the journal eccentricity is assumed to 
remain constant, resulting in an axisymmetric oil-film constraint. However, transient conditions that are prevalent in engine dynamics can lead to small perturbations that render the assumption relating to a constant eccentricity void. Under dynamic conditions the journal eccentricity alters and the hydrodynamic oil-film reaction occurs as a result of combined lubricant-entraining and squeeze-film motions $[\mathbf{5 7}, \mathbf{5 8}]$.

In general, while the inclusion of greater detail improves the accuracy of the simulation results, it can lead to both computational impracticality and model verification problems through experimentation or undertaking closed-form analytical solutions. It is hard to envisage the optimum level of detail required for the investigation of a given problem. The prudent approach is to undertake a parameter sensitivity and selection process as highlighted for some practical powertrain problems by Rahnejat [58], Kelly and Rahnejat [59], Rahnejat et al. [60] and Biermann and Hagerodt [61]. Drawing on past experience and paying attention to the underlying physical phenomena, which are deemed as responsible sources for excitation, invariably leads to the creation of simpler models with an 'optimum' level of detail. Returning to the case of crankshaft dynamics, it is clear that a growing trend towards low weight to high power output engines has resulted in greater torsional deflection vibration problems. Therefore, the inclusion of modules for realistic representation of the combustion process, component flexibility and support systems is apparent. Boysal and Rahnejat $[57,62]$ outline multibody dynamic models for single-cylinder, four-stroke engines comprising inertial components and assembly constraints, supported by hydrodynamic finite-width journal bearings and subjected to a combustion process. The necessary detail to investigate the secondary tilting motion of the piston and combined torsional vibration and conical whirling motion of the crankshaft includes the evaluation of main journal bearing hydrodynamic restoring reactions, friction torque, piston slapping action against the cylinder bore, piston friction and piston compression ring to cylinder wall elastohydrodynamic reaction. The authors show that inclusion of such detail can lead to long computation times on powerful platforms (in this case $8-12 \mathrm{~h}$ on an SGI Indy 5000 workstation). However, for the simulation study to be of any practical use in industry, this level of detail can be viewed as a mere prerequisite. The problem to be addressed from a design engineering point of view is to determine, for example, the required torque output and duration for a starter motor to overcome the friction torque in the crankshaft system and reach a steady state rotational speed with minimal inertial induced fluctuations.

With the desire for higher engine operating torques (e.g. peak combustion forces in the region of $20-40 \mathrm{kN}$ in $1.6-1.8 \mathrm{~L}$ diesel engines), large bearing loads are experienced which lead to both unstable whirl (mani- fested by flywheel wobble or nodding with a translational amplitude $0.05-0.5 \mathrm{~mm}$ ) and thin shell bearing failures. The need for representation of component flexibility and damping in multi-body engine models is, therefore, evident. It is clear that there are two levels of the same problem in the traditional sense: one relating to the large displacement rigid body dynamics of the crankshaft system and the other to the infinitesimal vibrations of bearings and flexible members. The traditional approach uses the former to predict the dynamic loads and obtain a steady reference position about which a linearized representation of the model can be subject to a finite element analysis for small perturbations. This approach, however, has some major limitations which include a piecemeal treatment of the problem based upon an 'averaged' rather than an instantaneous analysis, time stepping mismatch between the various forms of analyses and loss of non-linear effects owing to the use of a linearization process. The remedy is to make a holistic solution within a single computation environment but with exclusion of unnecessary detail. For the analysis of torsional deflection modes of the crankshaft system, Okamura et al. [63-65] have shown that dynamic stiffness and damping matrices for individual elements of an engine model can be concatenated into an overall matrix within the dynamic stiffness matrix method (DSMM) as a multi-body approach. This enables the representation of the crankshaft as a three-dimensional structure, allowing both its in-plane and out-of-plane flexible body modes to be ascertained. The solution is then obtained in the frequency domain but lacks the forced operating conditions owing to inertial imbalances as well as sources of non-linearity introduced by assembly constraints.

The sources of non-linearity include contact/impact problems, for instance, slapping of the piston skirt against the cylinder bore, caused by the offset assembly position of the wrist pin bearing from the axis of symmetry of the piston itself which brings the centre of gravity of the assembly ahead of the piston axis. An analysis of this motion is provided in reference [58] with the detailed contact conditions described by Knoll and Peeken [66]. Another source of non-linearity is the jump phenomenon in the dynamic behaviour of supporting journal bearings, where under unchanged load and speed conditions the vibrating crankshaft can jump from one seemingly stable position to another. This phenomenon has been observed experimentally by Kryniski [67] and through multi-body analysis by complex crankshaft orbits by Boysal and Rahnejat [57, 62] and Zeischka et al. [53].

Impact loading problems account for a good proportion of unexpected spectral noise and vibration contributions in powertrain systems, usually in the higher-frequency regions. This is a growing area for multi-body dynamic analysis and includes the analysis of impact problems through backlash in gears. Such 
problems include gear rattle [61], clutch pedal noise and vibration $[59,60,68,69]$ and driveline clonk [61, 70-72].

Multi-body dynamics has come a long way since the gyrodynamic analyses reported by Euler [8] and refined by Gammel [17]. More than 300 years since the inception of Newton-Euler equations and 200 years since Lagrange, their pioneering contributions have begun to make significant in-roads in the design and analysis of complex modern vehicles, machines and mechanisms.

\section{VEHICLE RIDE AND HANDLING}

Since the initial vehicle handling analysis by McHenry [22] a considerable volume of research has been devoted to multi-body studies of vehicle motion under steady or transient conditions. Many of these analyses have been concerned with either ride comfort of vehicles in traversing over topographic terrain irregularities such as bumps or ditches, or vehicle handling characteristics in response to various steering commands or road and environmental disturbances such as banking on slopes or facing a wind gust. The main issue in ride comfort is to isolate the occupants from sudden and often sharp road disturbances. This is a primary function of vehicle suspension, which also maintains the wheels at the right orientation to the road surface and controls the vehicle directional response. Often, for good ride comfort the suspension system should provide a relatively low vertical stiffness (particularly for off-road vehicles) which conflicts with the requirements for a good handling analysis that usually calls for a relatively high value of stiffness (critical for racing vehicles). These conflicting requirements have led to the gradual introduction of independent suspensions, adjustable systems and active elements. Multi-body dynamics has played an important role in these developments, initially through the use of linear vehicle dynamic models, as in the work reported by Segel [21] for lateral accelerations up to $0.3 \mathrm{~g}$.

The linear models embody some significant assumptions, including small steering inputs at normal constant vehicle speeds, linear tyre behaviour with slip and camber angles, smooth flat roads and lateral tyre forces being insensitive to small changes in the vertical tyre forces. In fact these represent grossly impractical conditions for most handling manoeuvres that a modern motor vehicle undergoes in normal use today. Sources of non-linearity exist in suspension kinematics, steering characteristics, tyre properties and vehicle body articulation as influenced by roll and pitching moments, as well as by significant longitudinal, lateral and lift forces. Other sources of non-linearity include stiffness and damping behaviour of suspension bump and rebound stops and shock absorbers.

\subsection{Suspension kinematics and compliance}

Ride and handling characteristics of a vehicle are largely affected by the front and rear suspension geometry and tyre-road interactions, as well as the inertial properties of the vehicle body, axles and powertrain and their spatial distribution. A convenient point to start is a kinematic analysis of the chosen suspension system, from a quarter-vehicle model, through half-vehicle models (front suspension and steering system or rear suspension system) to an ultimate non-linear full-vehicle handling model. The procedure for such analyses is described in reference [58].

The dual design requirements for the aforementioned conflicting ride comfort and responsive handling of vehicles have become largely realizable with the advent of independent suspensions, particularly with the development and use of the short long arm (SLA) configuration in the United States. This configuration is referred to as the double-wishbone suspension in the United Kingdom. The advantages are in the desensitization of the system to steering-induced shimmy and wheel tramp during hard braking. Independent suspensions also enable larger deflections and a greater roll resistance for a given vertical wheel rate, when compared with the solid live axles. Finally, the position of the roll centre can be altered by geometrical reconfiguration through main control parameters. These include the relative angles between the upper and the lower control arms, the angle between the latter and the horizontal, the control arm lengths and the ratio of the lower control arm length to the track [58, 73]. The choice of these parameters has, as its main effect, the determination of the suspension roll centre, the height of which above the ground profoundly affects the vehicle handling performance.

During cornering manoeuvres the upper control arm moves more than the lower control arm. As a result, the inside wheel moves upwards owing to rebound, while the outside wheel moves downwards because of jounce. These bounce, roll and pitch motions of the vehicle are determined by the suspension dynamics, governed by kinematic assembly constraints and system compliances [58]. For the kinematic structure of various suspensions, the reader is referred to specialist texts on the subject [73-75]. The manual adjustment of the above-mentioned suspension control parameters are commonplace, for instance, in suspension rate and roll centre height adjustments in luxury four wheel drive vehicles that are intended for the dual purposes of off-road and motorway driving performance. The trend, however, is to effect these changes in an automatic manner, through the use of active suspensions (for a survey of these, see references [76] to [78]).

The compliance characteristics of suspension systems are provided by suspension bushings, the spring rate and the shock absorber damping which are usually measured 
for vertical, lateral and yaw degrees of freedom. These sources of compliance allow the entire suspension assembly to deflect with the application of lateral tyre forces and aligning moments. The deflections cause the wheels to camber, steer and vertically and laterally displace. These provide compliance steer, compliance camber and lateral and vertical compliances. The vehicle designer can usually change the compliance characteristics of a suspension by changing the spring rate and the stiffness of the bushing elements. An extensive study of the influence of suspension parameters, including the suspension compliances in vehicle dynamics, has been reported by Riede et al. [79].

\subsection{Tyre models}

The pneumatic tyres, representing the interaction points between a vehicle and the road surface, play a significant role in vehicle handling through the generation of contact forces and moments. A good estimation of these forces under various steady and transient vehicle manoeuvres is a prerequisite for a realistic vehicle handling analysis. Tyre models for vehicle handling applications may be divided into two main categories: those employing measured data in a graphical or tabulated format or those using empirically obtained formulae [80]. The former have been widely used, with measured data acquired from pure cornering or pure braking conditions. An interpolation routine is then employed within a handling analysis to extract the tyre forces and moments under given simulation conditions. Although Fonda [81] and Nordeen and Cortese [82] have shown that all tyre forces and moments can be measured for different inflation pressures, camber and slip angles, the range of loading conditions, especially at high loads, is insufficient to cover the full range of data required for vehicle handling simulation studies. This shortcoming has led to the development of empirical formulae that can be used for tyre representation under all loading conditions. However, there are also a number of problems with this approach, chiefly that empirical formulae are usually related to steady state conditions and that a close curve fit to experimental characteristics, based upon a Fourier series or a polynomial representation, requires a relatively large number of coefficients [83]. Furthermore, extrapolation beyond the fitted range can yield large deviations from the actual prevailing conditions.

In general, the tyre models become more complex with larger magnitudes of wheel slip and conditions pertaining to combined slip in lateral and longitudinal modes. Furthermore, with the inclusion of the influence of camber, small changes in the vertical force affect the calculation of the lateral force. A modification in the value of lateral stiffness with camber change can accommodate for this, which in turn can significantly affect the predicted aligning torque at higher values of slip angle. Nevertheless,
Pacejka and Bakker [84] have successfully developed a tyre model to describe the tyre side force and the selfaligning torque as a function of slip angle and the brake force as a function of longitudinal slip. However, the formula is limited to steady state conditions during pure cornering, pure braking and combined lateral and longitudinal slip. The presented model provides features for the modification of tyre lateral force and aligning moment, combining them with the longitudinal force to enable combined cornering with braking. This model has come to be known as the magic formula and is extensively used in commercial codes for tyre modelling. For a comprehensive survey of tyre modelling methods, the reader is referred to reference [85].

\subsection{Assessment of vehicle handling behaviour}

The steady state handling performance of a vehicle is concerned with its directional behaviour when subjected to time invariant conditions. For instance, a steady state turn results when a vehicle negotiates a corner of constant curvature with a constant forward speed. The tyres develop appropriate slip angles and lateral forces. The relationship between the front and rear slip angles is an important determining factor in the handling characteristics of the vehicle. A handling diagram was introduced by Pacejka [86] which examines the variation in lateral acceleration with the difference between the rear and front slip angles. By constructing the corresponding boundaries for under and oversteer cases in the handling diagram, the stability of the steady state motion for different forward speeds can be investigated [87]. A source of instability in negotiating a turn is the oversteer or drift of the rear axle. In some cases, this is an indication of an insufficient rear axle stiffness, thus acting as a pointer for suspension design modifications.

In practice, all the intended production models are subjected to steady state handling tests which can include: a constant radius test, a constant forward speed test and a constant steer angle test. Measured parameters of interest include yaw velocity or lateral acceleration, obtained by a rate gyro or an accelerometer respectively. The ratios of yaw velocity and lateral acceleration to the steer angle are termed yaw velocity and lateral acceleration gains respectively. These can be obtained for different constant cornering speeds as measures of vehicle handling performance.

The steady state manoeuvres are kinematic representations of vehicle motions, prescribed by position and velocity relations in much the same way as for planetary motions described by Kepler [3] in his treatise in 1609. The vehicle mass and inertial properties are thus ignored. The lateral acceleration gain as a fraction of $g$ increases with the square of the forward tangential speed in steady state cornering. As Kepler observed, planets orbit the Sun such that the radius vectors connecting 


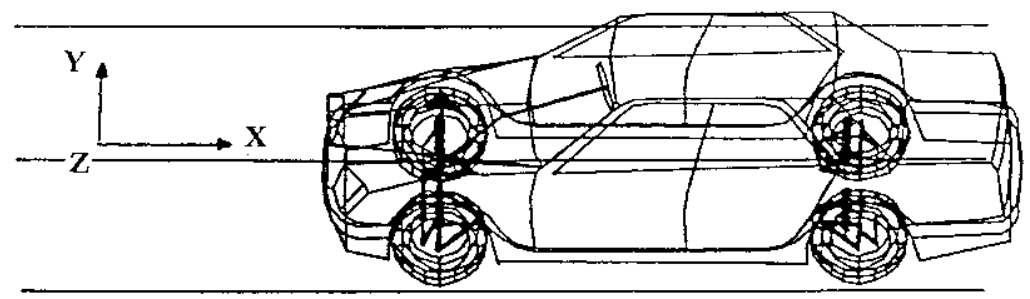

(a)

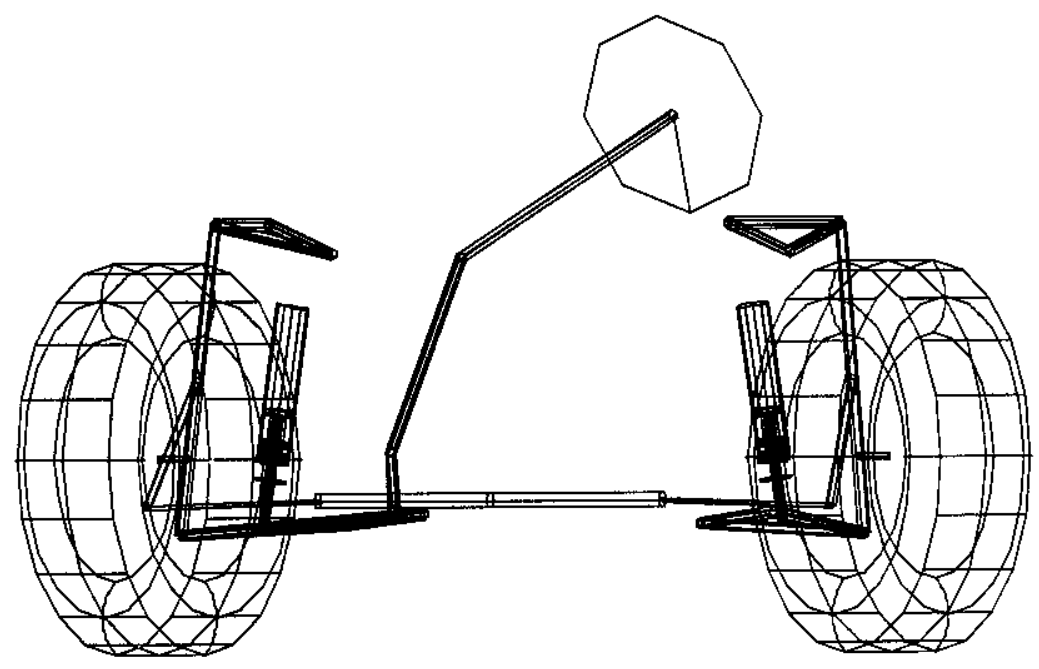

(b) $\stackrel{1}{4}_{x}$

Fig. 1 (a) Full-vehicle model and (b) front suspension and steering system model

them and the Sun sweep out equal areas in equal times. The same condition exists in the steady motion of a vehicle in a constant radius turn. Kepler's steady motion treatise, based upon the observations of Brahe, could not account for the elliptical orbital paths of the planets. In the absence of a physical explanation he resorted to describing the problem as an anomaly. An explanation for this so-called anomaly was of course found by Newton [6] some half-century later with the discovery of gravitation. This points to the fundamental concept that, in a steady state motion, the body, as a particle, is observed with respect to a set of axes that undergo the same transformations as itself, about which the inertial properties remain unchanged at all times. Under such conditions the vehicle motion approximates the kinematics of a particle in an ideal steady motion where slip angles for the front and rear tyres must necessarily equate and the steer angle required to negotiate a curve becomes independent of the forward speed. This con- dition is referred to as neutral steer. Although other steer conditions such as understeer and oversteer are also commonly considered with steady state motion, the steer angle with these becomes a function of $g$ and the route taken by the vehicle deviates from the prescribed path. This problem is exacerbated by increasing the forward speed of the vehicle which subjects the vehicle to an increasing centrifugal acceleration that can be regarded as a local gravitational effect as a fraction of $g$. This local gravitation effect abrogates the notion of a steady state motion. The implications for vehicle handling is that for low forward speeds one may just rely on the steady motion analyses, but, as the local gravitation effects (i.e. lateral accelerations) increase, a relative motion analysis must be considered where the motion (in the case of vehicle cornering) should be described in terms of a fixed global frame of reference about which inertial dynamics of the body change continually. Such an analysis is termed transient vehicle handling which 
refers to the vehicle behaviour resulting from the application of a steering command.

Among the many parameters that affect the handling performance of a vehicle, resulting in its transient response, are the suspension articulation, body roll and the generation of unequal front and rear and inside and outside wheel slip angles in a turn. Most modern vehicles can negotiate a turn in a stable manner with lateral accelerations up to $0.8 \mathrm{~g}$, during which a body roll in the region of $1-5^{\circ}$ can occur, depending on vehicle inertia, suspension geometry and compliance. With an independent suspension, and depending on its configuration, wheel camber would be expected to vary in the range of 20-75 per cent of the roll angle. This usually translates into increased tyre forces at the outside wheels and a corresponding decrease at the inside wheels. With the normal oversteer the inside rear wheel suffers the lowest tyre forces, which become the determining factor in the vehicle roll stability. Therefore, in a handling analysis the limiting conditions would be sought where, as a result of negotiating a particularly sharp corner or at a high forward speed or both, the inside rear wheel begins to off-load. Clearly, lowering the vehicle roll axis, reducing mass and inertia, stiffening the rear axle and utilizing the aerodynamic forces to increase the contact patch at the rear wheels (for example, with the use of an inverted spoiler) make it possible to enhance the cornering stability of the vehicle, as in Formula 1 racing cars, achieving lateral accelerations of 1.5-2.5 $\mathrm{g}$. These solutions, however, remain by and large impractical for normal vehicles for obvious reasons.

In practice, many simulation tests have been devised by the manufacturers to ascertain the handling performance of their production models. These include lane change manoeuvres, cornering with or without braking, double lane changes and slalom testing. Various terrains can be modelled, as well as road profiles, textures and conditions. With an increased level of sophistication in multi-body formulation and ease of access to parametrized commercial models such as ADAMS CAR, progressively such tests are being conducted during the design process and termed virtual prototyping simulations. For a number of examples of this approach, the reader is referred to references [58] and [86] to [95]. Below, a multi-body full-vehicle model is briefly described and the results of a lane change test are highlighted.

Table 1 Inertial members in the full-vehicle model

\begin{tabular}{|c|c|c|c|c|c|}
\hline \multirow[b]{2}{*}{ Number } & \multirow[b]{2}{*}{ Part name } & \multirow{2}{*}{$\begin{array}{l}\text { Mass } \\
(\mathrm{kg})\end{array}$} & \multicolumn{3}{|c|}{ Inertia $\left(\mathrm{kg} \mathrm{mm}^{2}\right)$} \\
\hline & & & $I_{x x}$ & $I_{y y}$ & $I_{z z}$ \\
\hline 1 & Ground & - & - & - & - \\
\hline 2 & Vehicle body & 1185 & $4.83 \mathrm{E}+08$ & $2.404 \mathrm{E}+09$ & $2.482 \mathrm{E}+09$ \\
\hline 3 & Steering rack & 4.1 & $1.84 \mathrm{E}+05$ & $1.84 \mathrm{E}+05$ & 460 \\
\hline 4 & Steering wheel & 2.1 & $1.3 \mathrm{E}+04$ & $1.3 \mathrm{E}+04$ & $2.4 \mathrm{E}+04$ \\
\hline 5 & Upper steering column & 1.6 & $8.5 \mathrm{E}+04$ & $8.5 \mathrm{E}+04$ & 80 \\
\hline 6 & Lower steering column & 1.1 & $3.4 \mathrm{E}+04$ & $3.4 \mathrm{E}+04$ & 40 \\
\hline 7 & Pinion & 0.8 & 3200 & 3200 & 77 \\
\hline 8 & Lower wishbone left & 6 & $5 \mathrm{E}+04$ & $1 E+05$ & $1.5 \mathrm{E}+05$ \\
\hline 9 & Lower wishbone right & 6 & $5 E+04$ & $1 \mathrm{E}+05$ & $1.5 \mathrm{E}+05$ \\
\hline 10 & Upper wishbone left & 0.6 & 3000 & 300 & 3000 \\
\hline 11 & Upper wishbone right & 0.6 & 3000 & 300 & 3000 \\
\hline 12 & Steering knuckle left & 14 & $8 \mathrm{E}+04$ & $1.3 \mathrm{E}+05$ & $8 E+04$ \\
\hline 13 & Steering knuckle right & 14 & $8 \mathrm{E}+04$ & $1.3 \mathrm{E}+05$ & $8 \mathrm{E}+04$ \\
\hline 14 & Tie rod left & 0.7 & 8200 & 8200 & 27 \\
\hline 15 & Tie rod right & 0.7 & 8200 & 8200 & 27 \\
\hline 16 & Upper ABS left & 15.12 & $1.4 \mathrm{E}+05$ & $1.4 \mathrm{E}+05$ & $2.7 \mathrm{E}+04$ \\
\hline 17 & Upper ABS right & 15.12 & $1.4 \mathrm{E}+05$ & $1.4 \mathrm{E}+05$ & $2.7 \mathrm{E}+04$ \\
\hline 18 & Lower ABS left & 1.68 & 6000 & 6000 & 200 \\
\hline 19 & Lower ABS right & 1.68 & 6000 & 6000 & 200 \\
\hline 20 & Lower wishbone left & 1.8 & $1.5 \mathrm{E}+04$ & $1 E+05$ & $2.4 \mathrm{E}+04$ \\
\hline 21 & Lower wishbone right & 1.8 & $1.5 \mathrm{E}+04$ & $1 \mathrm{E}+05$ & $2.4 \mathrm{E}+05$ \\
\hline 22 & Upper wishbone left & 1.3 & 7000 & $1.5 \mathrm{E}+04$ & $2.1 \mathrm{E}+04$ \\
\hline 23 & Upper wishbone right & 1.3 & 7000 & $1.5 \mathrm{E}+04$ & $2.1 \mathrm{E}+04$ \\
\hline 24 & Steering knuckle left & 13.8 & $8.2 \mathrm{E}+04$ & $1.31 \mathrm{E}+05$ & $8.2 \mathrm{E}+04$ \\
\hline 25 & Steering knuckle right & 13.8 & $8.2 \mathrm{E}+04$ & $1.31 \mathrm{E}+05$ & $8.2 \mathrm{E}+04$ \\
\hline 26 & Tie rod left & 0.7 & 8200 & 8200 & 27 \\
\hline 27 & Tie rod right & 0.7 & 8200 & 8200 & 27 \\
\hline 28 & Upper ABS left & 15.12 & $1.4 \mathrm{E}+05$ & $1.4 \mathrm{E}+05$ & $2.7 \mathrm{E}+04$ \\
\hline 29 & Upper ABS right & 15.12 & $1.4 \mathrm{E}+05$ & $1.4 \mathrm{E}+05$ & $2.7 \mathrm{E}+04$ \\
\hline 30 & Lower ABS left & 1.68 & 6000 & 6000 & 200 \\
\hline 31 & Lower ABS right & 1.68 & 6000 & 6000 & 200 \\
\hline 32 & Front tyre left & 42.2 & $9 \mathrm{E}+05$ & $9 \mathrm{E}+05$ & $1.59 \mathrm{E}+06$ \\
\hline 33 & Front tyre right & 42.2 & $9 \mathrm{E}+05$ & $9 \mathrm{E}+05$ & $1.59 \mathrm{E}+06$ \\
\hline 34 & Rear tyre left & 42.2 & $9 \mathrm{E}+05$ & $9 \mathrm{E}+05$ & $1.59 \mathrm{E}+06$ \\
\hline 35 & Rear tyre right & 42.2 & $9 E+05$ & $9 E+05$ & $1.59 \mathrm{E}+06$ \\
\hline
\end{tabular}




\subsection{Full-vehicle handling simulation}

Figure 1a shows a schematic representation of a fullvehicle model, comprising vehicle mass and inertia, front and rear axles, front and rear SLA suspensions, a rack and pinion steering system, road wheels and tyres. Figure $1 \mathrm{~b}$ illustrates the multi-body model of the front suspension and steering system in more detail. The list of parts in the model and their inertial properties are provided in Table 1. Vehicle motions are described in terms of the fixed global frame of reference $X, Y, Z$ shown in Fig. 1. Local part frames of reference $x_{i}, y_{i}, z_{i}$ are attached to all the moving parts $i$. A generic formulation method, based upon Lagrange's equation for constrained systems, is employed for the derivation of equations of motion for all parts in the model in a body 3-1-3 Euler frame of reference. The generalized formulation and solution methods are comprehensively covered in reference [58].

Assembly of parts in the model is achieved using joints and primitive constraints, each of which is represented by one or a number of holonomic algebraic constraint functions. A list of the assembly constraints in the vehicle model is provided in Table 2 .

The model incorporates the sources of compliance in the independent front and rear suspensions, as well as in the steering system. These include the various suspension bushings and mounts, springs and shock absorbers, jounce and rebound bumpers and steering system bushings. Many of these have non-linear characteristics as referred to in Table 3 and are shown by the characteristic curves in Fig. 2.

The tyre model is described in reference [58]. The test track is a simulated flat three-lane motorway section. The motion of the vehicle is a lane change, determined by a defined steering constraint function of an initial right turn by $80^{\circ}$, followed by a counter left turn steer of $60^{\circ}$. The forward speed of the vehicle is $30 \mathrm{~m} / \mathrm{s}$ (approximately $110 \mathrm{~km} / \mathrm{h}$, the speed limit for motorway driving in the United Kingdom). The maximum lateral acceleration of the vehicle during this manoeuvre is $0.7 \mathrm{~g}$.

The Grüebler-Kützbach expression can be used to determine the available degrees of freedom in the vehicle model. There are 34 parts in the vehicle model, excluding ground (see Table 1). The number of constraints for each joint, coupler and specified motions is given in Table 2. Thus

$$
n_{\mathrm{DOF}}=6 n-\Sigma C=6 n-m=6(34)-110=94
$$

The full description of the vehicle model with a nonlinear transient dynamic analysis in cornering is provided by Hegazy et al. [96]. Here transient analysis for a lane change manoeuvre is presented.

Table 2 Constraints in the full-vehicle model

\begin{tabular}{|c|c|c|c|c|}
\hline Number & Constraint type & Part I & Part J & $\begin{array}{l}\text { Number of } \\
\text { constraint }\end{array}$ \\
\hline 1 & Revolute joint 26 & Steering wheel & Upper steering column & 5 \\
\hline 2 & Revolute joint 33 & Upper steering column & Vehicle body & 5 \\
\hline 3 & Universal joint & Upper steering column & Lower steering column & 4 \\
\hline 4 & Universal joint & Lower steering column & Pinion & 4 \\
\hline 5 & Cylindrical joint 54 & Pinion & Vehicle body & 4 \\
\hline 6 & Translational joint 61 & Steering rack & Vehicle body & 5 \\
\hline 7 & Spherical joint & Lower wishbone left & Steering knuckle left & 3 \\
\hline 8 & Spherical joint & Lower wishbone right & Steering knuckle right & 3 \\
\hline 9 & Spherical joint & Upper wishbone left & Steering knuckle left & 3 \\
\hline 10 & Spherical joint & Upper wishbone right & Steering knuckle right & 3 \\
\hline 11 & Spherical joint & Steering knuckle left & Tie rod left & 3 \\
\hline 12 & Spherical joint & Steering knuckle right & Tie rod right & 3 \\
\hline 13 & Universal joint & Steering rack & Tie rod left & 4 \\
\hline 14 & Universal joint & Steering rack & Tie rod right & 4 \\
\hline 15 & Cylindrical joint & Upper ABS left & Lower ABS left & 4 \\
\hline 16 & Cylindrical joint & Upper ABS right & Lower ABS right & 4 \\
\hline 17 & Spherical joint & Lower wishbone left & Steering knuckle left & 3 \\
\hline 18 & Spherical joint & Lower wishbone right & Steering knuckle right & 3 \\
\hline 19 & Spherical joint & Upper wishbone left & Steering knuckle left & 3 \\
\hline 20 & Spherical joint & Lower wishbone right & Steering knuckle right & 3 \\
\hline 21 & Spherical joint & Steering knuckle left & Tie rod left & 3 \\
\hline 22 & Spherical joint & Steering knuckle right & Tie rod right & 3 \\
\hline 23 & Cylindrical joint & Upper ABS left & Lower ABS left & 4 \\
\hline 24 & Cylindrical joint & Upper ABS right & Lower ABS right & 4 \\
\hline 25 & Revolute joint & Steering knuckle left & Front tyre left & 5 \\
\hline 26 & Revolute joint & Steering knuckle right & Front tyre right & 5 \\
\hline 27 & Revolute joint & Steering knuckle left & Rear tyre left & 5 \\
\hline 28 & Revolute joint & Steering knuckle right & Rear tyre right & 5 \\
\hline 29 & Coupler & Joint 54 & Joint 61 & 1 \\
\hline 30 & Motion & Joint 26 & Joint 26 & 1 \\
\hline 31 & Motion & Joint 33 & Joint 33 & 1 \\
\hline
\end{tabular}


Table 3 Sources of compliance in the full-vehicle model

\begin{tabular}{|c|c|c|c|c|c|c|c|}
\hline \multirow[b]{2}{*}{ Number } & \multirow[b]{2}{*}{ Force name } & \multicolumn{3}{|c|}{ Bushing stiffness } & \multicolumn{3}{|c|}{ Bushing viscous damping } \\
\hline & & $k_{x}$ & $k_{y}$ & $k_{z}$ & $C_{x}$ & $C_{y}$ & $C_{z}$ \\
\hline 1 & Upper wishbone front mount left & $3 E+4$ & $3 \mathrm{E}+4$ & See Fig. 2 & 50.1 & 50.1 & 0.35 \\
\hline 2 & Upper wishbone front mount right & $3 E+4$ & $3 \mathrm{E}+4$ & See Fig. 2 & 50.1 & 50.1 & 0.35 \\
\hline 3 & Upper wishbone rear mount left & $3 \mathrm{E}+4$ & $3 \mathrm{E}+4$ & See Fig. 2 & 50.1 & 50.1 & 0.35 \\
\hline 4 & Upper wishbone rear mount right & $3 \mathrm{E}+4$ & $3 \mathrm{E}+4$ & See Fig. 2 & 50.1 & 50.1 & 0.35 \\
\hline 5 & Lower wishbone front mount left & $1.5 \mathrm{E}+4$ & $1.5 \mathrm{E}+4$ & 3200 & 83.6 & 25.1 & 5.4 \\
\hline 6 & Lower wishbone front mount right & $1.5 \mathrm{E}+4$ & $1.5 \mathrm{E}+4$ & 3200 & 83.6 & 25.1 & 5.4 \\
\hline 7 & Lower wishbone rear mount left & 1500 & 1500 & 1000 & 1.25 & 1.25 & 0.85 \\
\hline 8 & Lower wishbone rear mount right & 1500 & 1500 & 1000 & 1.25 & 1.25 & 0.85 \\
\hline 9 & Upper wishbone front mount left & $3 E+4$ & $3 \mathrm{E}+4$ & See Fig. 2 & 50.1 & 50.1 & 0.35 \\
\hline 10 & Upper wishbone front mount right & $3 \mathrm{E}+4$ & $3 E+4$ & See Fig. 2 & 50.1 & 50.1 & 0.35 \\
\hline 11 & Upper wishbone rear mount left & $3 \mathrm{E}+4$ & $3 \mathrm{E}+4$ & See Fig. 2 & 50.1 & 50.1 & 0.35 \\
\hline 12 & Upper wishbone rear mount right & $3 \mathrm{E}+4$ & $3 \mathrm{E}+4$ & See Fig. 2 & 50.1 & 50.1 & 0.35 \\
\hline 13 & Lower wishbone front mount left & $3.3 \mathrm{E}+4$ & $3.3 \mathrm{E}+4$ & 3200 & 180 & 55 & 5.35 \\
\hline 14 & Lower wishbone front mount right & $3.3 \mathrm{E}+4$ & $3.3 \mathrm{E}+4$ & 3200 & 180 & 55 & 5.35 \\
\hline 15 & Lower wishbone rear mount left & $3.3 \mathrm{E}+4$ & $3.3 \mathrm{E}+4$ & 3200 & 180 & 55 & 5.35 \\
\hline 16 & Lower wishbone rear mount right & $3.3 \mathrm{E}+4$ & $3.3 \mathrm{E}+4$ & 3200 & 180 & 55 & 5.35 \\
\hline 17 & Tie rod bushing left & 1000 & 3000 & 3000 & 8.3 & 8.3 & 8.3 \\
\hline 18 & Tie rod bushing right & 1000 & 3000 & 3000 & 8.3 & 8.3 & 8.3 \\
\hline 19 & Upper ABS mount left & 2000 & 2000 & 6000 & 1.7 & 1.7 & 5.1 \\
\hline 20 & Upper ABS mount right & 2000 & 2000 & 6000 & 1.7 & 1.7 & 5.1 \\
\hline 21 & Upper ABS mount left & 2000 & 2000 & 6000 & 1.7 & 5.1 & 5.1 \\
\hline 22 & Upper ABS mount right & 2000 & 2000 & 6000 & 1.7 & 5.1 & 5.1 \\
\hline 23 & Lower ABS mount left & 2000 & 2000 & 6000 & 1.7 & 5.1 & 5.1 \\
\hline 24 & Lower ABS mount right & 2000 & 2000 & 6000 & 1.7 & 5.1 & 5.1 \\
\hline 25 & Lower ABS mount left & 2000 & 2000 & 6000 & 1.7 & 1.7 & 5.1 \\
\hline 26 & Lower ABS mount right & 2000 & 2000 & 6000 & 1.7 & 1.7 & 5.1 \\
\hline 27 & Spring force left & \multicolumn{6}{|c|}{ Single-component force, see Fig. 2} \\
\hline 28 & Spring force right & \multicolumn{6}{|c|}{ Single-component force, see Fig. 2} \\
\hline 29 & Damper force left & \multicolumn{6}{|c|}{ Single-component force, see Fig. 2} \\
\hline 30 & Damper force right & \multicolumn{6}{|c|}{ Single-component force, see Fig. 2} \\
\hline 31 & Bump stop left & \multicolumn{6}{|c|}{ Single-component force, see Fig. 2} \\
\hline 32 & Bump stop right & \multicolumn{6}{|c|}{ Single-component force, see Fig. 2} \\
\hline 33 & Rebound stop left & \multicolumn{6}{|c|}{ Single-component force, $k=3700$} \\
\hline 34 & Rebound stop right & \multicolumn{6}{|c|}{ Single-component force, $k=3700$} \\
\hline 35 & Spring force left & \multicolumn{6}{|c|}{ Single-component force, see Fig. 2} \\
\hline 36 & Spring force right & \multicolumn{6}{|c|}{ Single-component force, see Fig. 2} \\
\hline 37 & Damper force left & \multicolumn{6}{|c|}{ Single-component force, see Fig. 2} \\
\hline 38 & Damper force right & \multicolumn{6}{|c|}{ Single-component force, see Fig. 2} \\
\hline 39 & Bump stop left & \multicolumn{6}{|c|}{ Single-component force, see Fig. 2} \\
\hline 40 & Bump stop right & \multicolumn{6}{|c|}{ Single-component force, see Fig. 2} \\
\hline 41 & Rebound stop left & \multicolumn{6}{|c|}{ Single-component force, $k=3700$} \\
\hline 42 & Rebound stop right & \multicolumn{6}{|c|}{ Single-component force, $k=3700$} \\
\hline 43 & Front left tyre force & \multicolumn{6}{|c|}{ Single-component force } \\
\hline 44 & Front right tyre force & Single-cor & ponent for & & & & \\
\hline 45 & Rear left tyre force & Single-cor & ponent for & & & & \\
\hline 46 & Rear right tyre force & Single-cor & ponent for & & & & \\
\hline
\end{tabular}

The interest in this simulation study is twofold:

(a) to ascertain the roll stability of the vehicle by monitoring its roll angle change and front and rear roll centre heights,

(b) to determine the vehicle stability by observing the tyre forces, particularly on the inside wheels.

For this class of vehicle a body roll in the range $2-8^{\circ}$ is expected under the specified conditions, during which the front and rear roll centres are anticipated to remain confined to maximum vertical excursions of 20-30 per cent of their value under static equilibrium conditions on a flat road.

Clearly, with such a detailed analysis it is possible to obtain a considerable amount of information that can be used in suspension refinement by modifications to geometry and compliance, and to acquire component loading data for a subsequent structural analysis. However, the results presented here are confined to the vehicle handling analysis.

A full-vehicle handling analysis should commence with the determination of the static equilibrium position of the vehicle. The physical implication of this is to place the vehicle model at the kerb height and obtain displacement of all parts, static deflection of compliant members and the initial forces and moments in the system model. The value of some of these parameters can be used to verify the correct assembly of parts in the 
Front upper control arni mounts

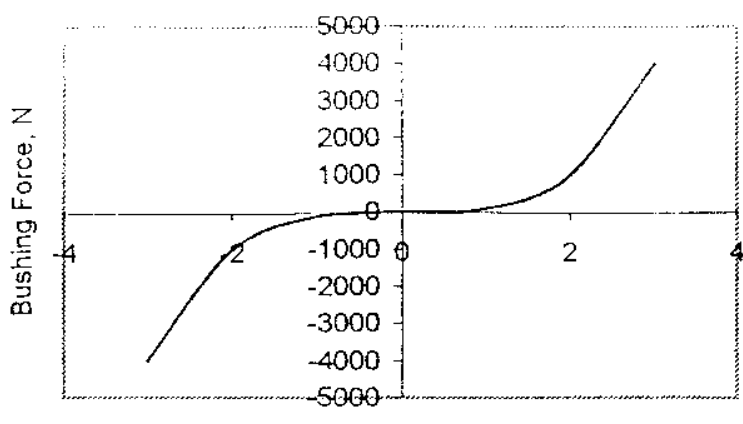

Bushing Deformation, $\mathrm{mm}$

(a) Sub-frante mounts

Front damper forces

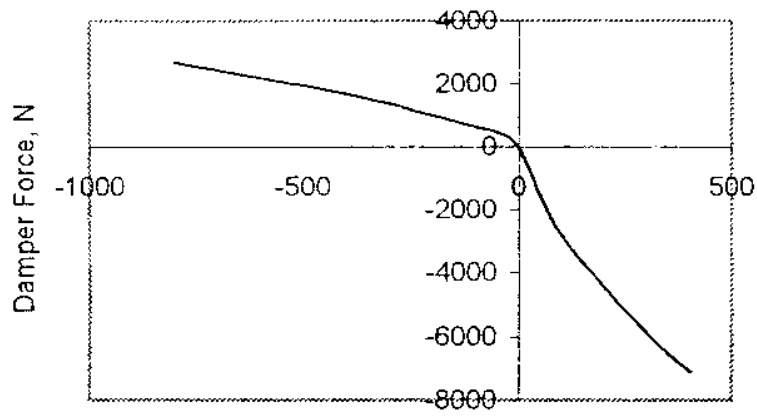

Damper Velocity, mm/s.

(c) Front damper characteristics

Rear Damper forces

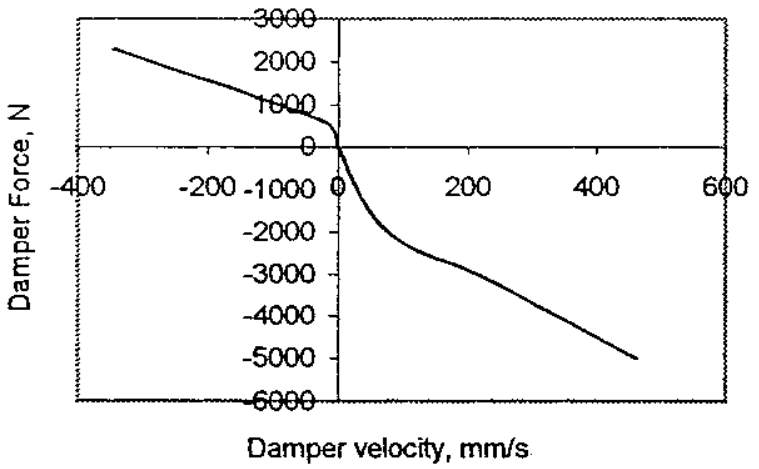

(e) Rear damper characteristics
Front spring forces

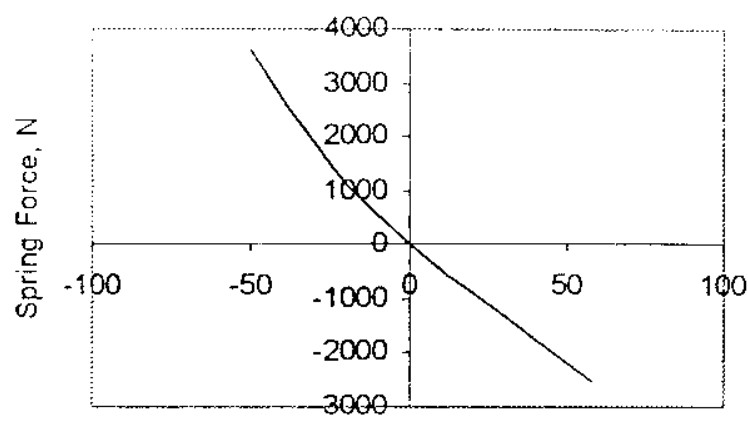

Spring deflection, mm

(b) Front spring characteristics

Rear spring forces

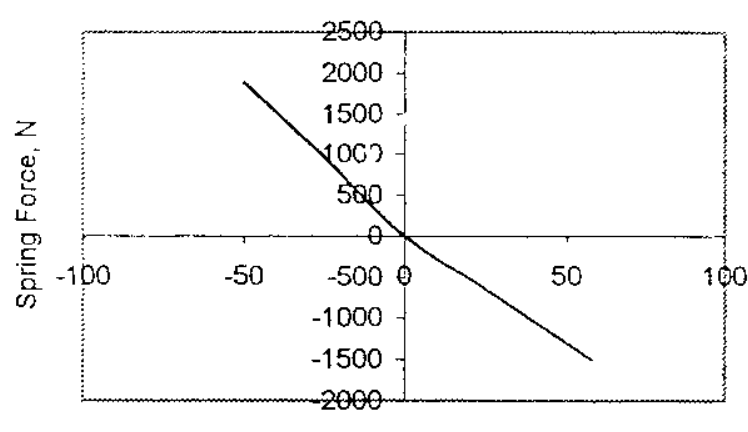

Spring deffection, $\mathrm{mm}$

(d) Rear spring characteristics

Front and rear bump stops

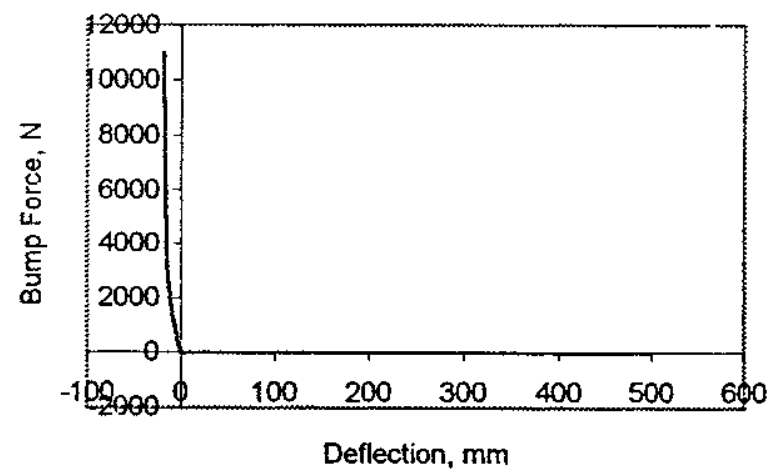

(f) Bump and rebound force characteristics

Fig. 2 Sources of compliance in the vehicle model

model, when cross-referenced against an actual physical prototype. Front and rear suspension roll centre heights and wheel camber angles under static equilibrium are used for this purpose. Static equilibrium cannot be obtained for vehicle models that have been assembled incorrectly, as this will invariably result in either the generation of high reactions or an overconstrained or a redundantly constrained degrees of freedom mechanism. The last condition leads to the generation of redundant algebraic functions. 


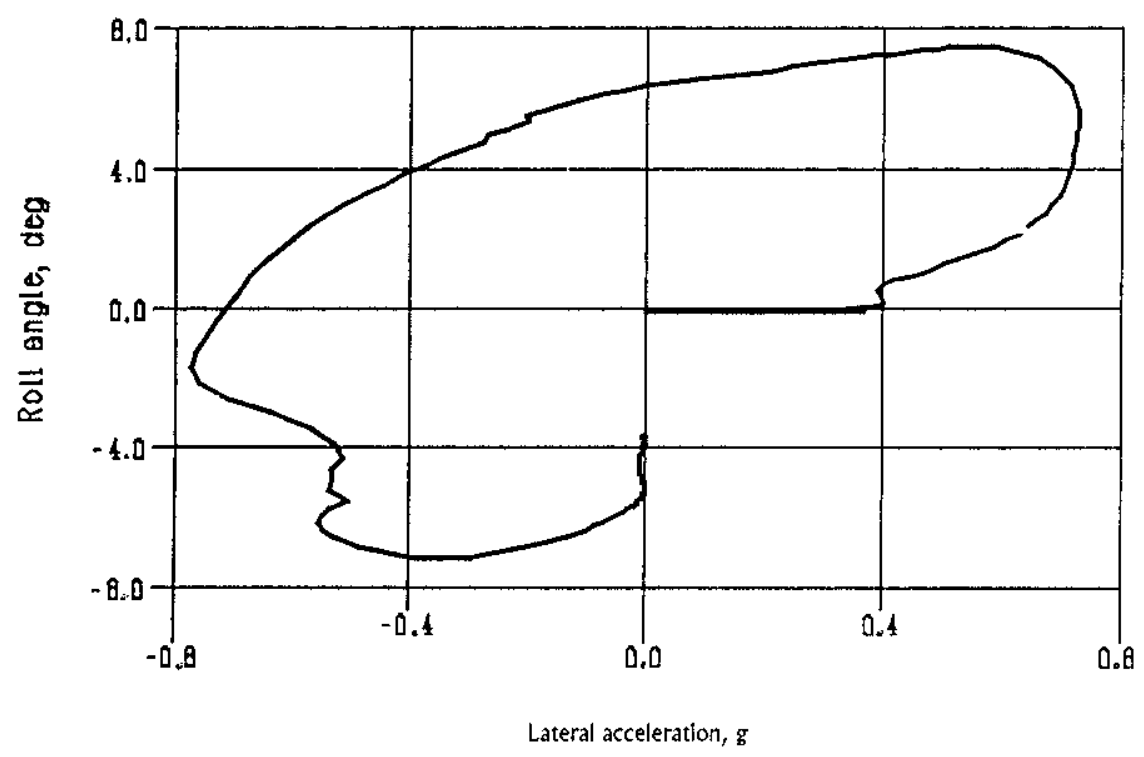

Fig. 3 Vehicle roll characteristics with lateral acceleration during lane change

Once the static equilibrium position is determined, the dynamic analysis based upon the conditions stated above is imposed instantaneously. However, vehicle acceleration from the rest position can be specified if that is desired.

During the lane change manoeuvre the inside wheels move upwards owing to rebound, while the outside wheels move downwards because of jounce. These movements are determined by the vehicle inertial dynamics, induced by the generation of tyre forces and controlled by the articulation of suspension elements. As a result, the body rolls as shown in Fig. 3 and the front and rear roll centres are displaced (see Fig. 4). Referring to Fig. 3, note that the vehicle initially rolls in one direction with the right-hand steer and then in the opposite direction with the counter left-hand steer, before returning to its no-roll steady straight line motion. A maximum body roll of $7^{\circ}$ has been observed which is within the aforementioned required performance criteria. The figure also shows that the lateral acceleration is increased during the manoeuvre, reaching a maximum value of $0.7 \mathrm{~g}$ during the right-hand steer and a gradual reduction, prior to an increased lateral acceleration in the opposite sense, with the counter lefthand steer.

The front and rear suspension roll centre heights for this vehicle under static equilibrium on a flat road are 65 and $68 \mathrm{~mm}$ respectively. Clearly, these are correctly obtained by the initial static analysis and shown in Fig. 4 at $t=0$. As the vehicle turns, the body rolls about its instantaneous

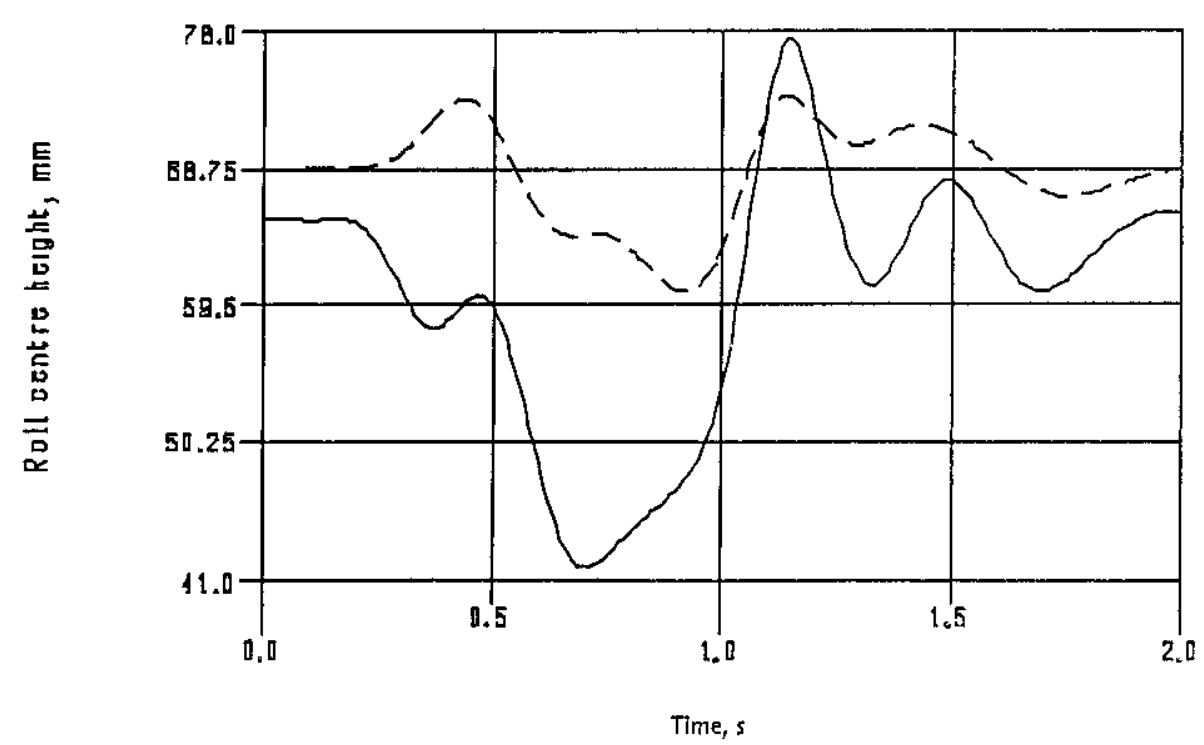

Crank ralt agntera halght - -Rar rall oentra halaht

Fig. 4 Front and rear roll centre height change during the manoeuvre 
roll axis (connecting the front and rear roll centres). The roll axis alters with yaw motion of the vehicle during the manoeuvre and pitches with the vertical excursions of front and rear suspensions. This amounts to a complex three-dimensional motion. Of interest to the vehicle designer is the optimum transient response, this being the fastest response with a minimum oscillatory behaviour in returning to steady conditions when the manoeuvre has been completed. Furthermore, vehicle stability during the manoeuvre is of vital interest. It can be observed, in Fig. 4, that the front and rear roll centres assume their steady equilibrium positions after a very short, small-amplitude oscillatory behaviour with the completion of the commanded steer at $t=1.2 \mathrm{~s}$. This is an acceptable response. It is also noted that the rises in roll centre heights, which can lead to vehicle instability, are small and well within the previously stated acceptable limits.
Another indication of vehicle stability is the generated tyre vertical forces. The diminution of this force on an inside wheel in a turn signifies loss of contact with the road surface. With the chosen manoeuvre the outside wheels in a turn experience an increase in their vertical tyre forces, while the inside wheels begin to off-load. Figures $5 \mathrm{a}$ and $\mathrm{b}$ illustrate this effect as the vehicle is subjected to combined right- and left-hand steers. The initial values at $t=0$ correspond to the load shares under static equilibrium, these clearly being higher for the rear tyres. The swift return of the tyre vertical forces to their steady value after the vehicle manoeuvre is a further indication of desired vehicle transient response. As the vehicle undergoes the lane change motion, the right and left tyres assume the inside turn position and their vertical tyre forces are decreased. However, the existence of sufficient forces is still indicated. The high-
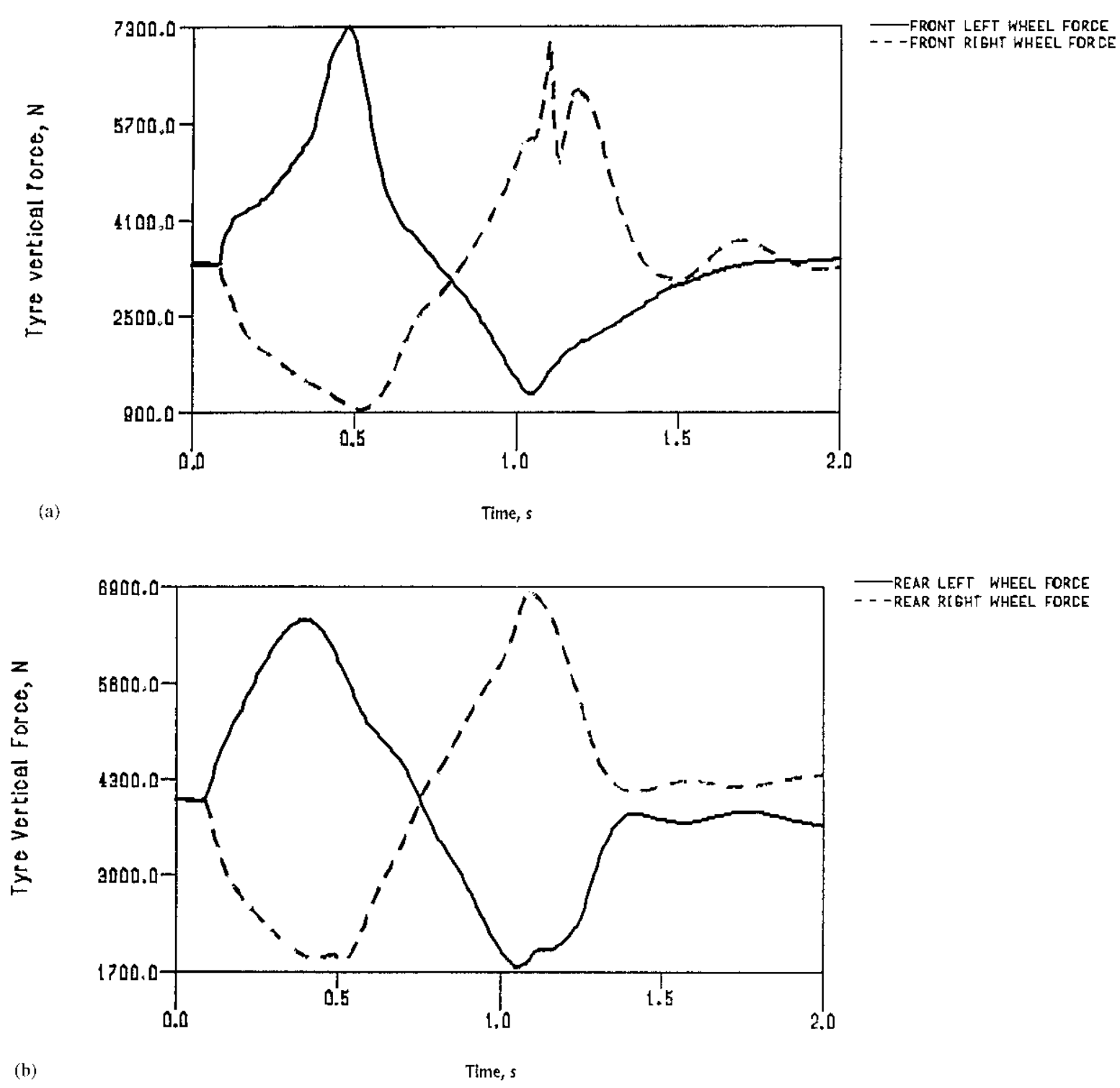

Fig. 5 (a) Front wheel and (b) rear wheel vertical tyre forces 
lighted simulation is typical of practical vehicle handling studies.

\section{SIMULATION OF MULTICYLINDER INTERNAL COMBUSTION ENGINES}

With improved ride and handling performance of vehicles (an example of which is described in Section 2.4), their noise and vibration characteristics have become progressively important. In both the developed and the developing world the lifestyle of many revolves around the use of motor vehicles. Furthermore, the proportion of time spent under idling conditions, or at low to moderate travel speeds, has increased markedly with traffic congestion. As a result, vehicle occupants as well as other road users are subject to noise sources that are predominantly contributed by the powertrain system, as opposed to those that are road induced or caused by aerodynamic effects. Recent surveys show that drivers are more annoyed by structure-borne noise and vibration than airborne noise, the former being at a lower frequency and almost entirely induced by the powertrain system.

The internal combustion engine, as a power source, is inherently unbalanced owing to the translational imbalance of the reciprocating elements (pistons and proportion of masses of connecting rods in translational motion) and the torsional deflection behaviour of engine components. The combustion process acts as the initiating source for the spectrum of noise and vibration in the powertrain system which includes its own fundamental forcing frequency (this being half the rotational frequency of the crankshaft for a four-stroke engine) and all its multiples. The effect of the combustion forces is firstly to introduce the imbalance inertial forces at the engine rotational frequency (i.e. engine order) and all its whole-order multiples (the even-order contributions being the most troublesome) and secondly to induce torsional deflection response of the engine block and the crankshaft system. The latter occurs at odd and halfengine orders. Rahnejat [58] provides a comprehensive analytical derivation for all these spectral contents for single and multicylinder engines. It also points to the experimental evidence for them. The reader is also referred to the experimental results reported by Dixon et al. [97], Kinoshita et al. [98], Nakada and Tonosaki [99] and March and Croker [100].

Provisions can be made for reductions in amplitudes of vibration of different engine orders. These include cylinder phasing, the introduction of balance masses and counter-rotating shafts to the crankshaft in order to minimize or eliminate some of the spectral contributions. Although this can be shown to be true through analytical studies, in reality the elastodynamic behaviour of the system precludes the elimination of any of the response components. To minimize their effects, the chance of unbalanced motions should be reduced. This necessitates the minimization of reciprocating masses while increasing the stiffness of engine components, a solution that leads to a paradox. Reducing the piston stroke and crankpin radius while increasing the connecting rod length can also reduce the higher-order effects. However, this can also lead to an adverse effect in terms of package space requirement for engine installation. Therefore, the problem is truly multivariate and requires detailed studies with specific aims in mind.

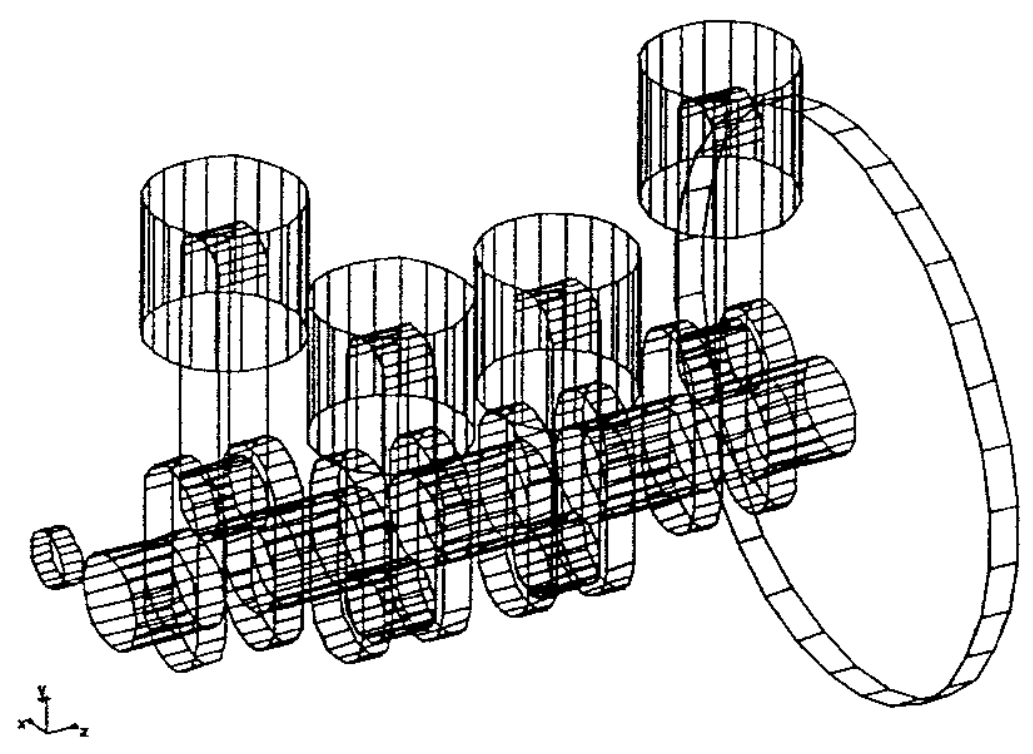

Fig. 6 Multi-body four-cylinder engine model 
Table 4 Parts in the multi-body four-cylinder engine model

\begin{tabular}{lllll}
\hline Part name & Mass $(\mathrm{kg})$ & $I_{x x}\left(\mathrm{~kg} \mathrm{~mm}^{2}\right)$ & $I_{y y}\left(\mathrm{~kg} \mathrm{~mm}^{2}\right)$ & $I_{z z}\left(\mathrm{~kg} \mathrm{~mm}^{2}\right)$ \\
\hline Pistons 1 to 4 & $0.5-0.8$ & $500-900$ & $500-900$ & $450-870$ \\
Conrods 1 to 4 & $0.8-1.0$ & $2 \mathrm{e} 3-5 \mathrm{e} 3$ & $400-650$ & $2 \mathrm{e} 3-5 \mathrm{e} 3$ \\
Crankpins 1 to 4 & $0.2-0.5$ & $75-90$ & $75-90$ & $100-150$ \\
Camgear & $0.03-0.07$ & $1.0-6.0$ & $1.0-6.0$ & $3.5-8.5$ \\
Journals 1 to 5 & $0.5-0.7$ & $150-175$ & $150-175$ & $200-275$ \\
Webs 1 to 8 & $0.5-0.9$ & $450-700$ & $90-200$ & $450-900$ \\
Flywheel & $7.0-10.0$ & $2 \mathrm{e} 4-5 \mathrm{e} 4$ & $2 \mathrm{e} 4-5 \mathrm{e} 4$ & $6 \mathrm{e} 4-8 \mathrm{e} 4$ \\
\hline
\end{tabular}

\subsection{Four-cylinder in-line gasoline engine model}

Figure 6 depicts a multi-body model of a four-stroke, four-cylinder, in-line internal combustion engine. The list of parts in the model and their mass and inertial properties are given in Table 4. The model components (flywheel, pistons and connecting rods) are considered as rigid inertial elements. The crankshaft is subdivided into a number of point mass/inertial components, interconnected by three-dimensional elastic fields, represented by dynamic stiffness and damping matrices (see references [58] and [63] to [65]). In this way the crankshaft webs are considered as rigid elements, each of which includes half the inertial contribution of each interconnecting crankpin or crank journal. The elasticity of the crank journal and the thin journal bearing shells are included in the model. A module, based upon a column model, is used to calculate the thin shell behaviour within an elastohydrodynamic evaluation of the lubricant-film thickness and pressure distribution in the main crankshaft bearings. A theoretical formulation of this is given in Section 3.3.

The employed constraints in the model are listed in Table 5. A translational joint is employed to constrain the motion of the piston to pure translation along the cylinder bore. This precludes its tilting motion, which results in piston slapping action, and reduces the com-

Table 5 Constraints in the multi-body four-cylinder engine model

\begin{tabular}{llll}
\hline Part I & Part J & $\begin{array}{l}\text { Constraint } \\
\text { type }\end{array}$ & $\begin{array}{l}\text { DOF } \\
\text { removed }\end{array}$ \\
\hline Piston 1 & Conrod 1 & Revolute & 5 \\
Piston 2 & Conrod 2 & Revolute & 5 \\
Piston 3 & Conrod 3 & Revolute & 5 \\
Piston 4 & Conrod 4 & Revolute & 5 \\
Piston 1 & Ground & Translational & 5 \\
Piston 2 & Ground & Translational & 5 \\
Piston 3 & Ground & Translational & 5 \\
Piston 4 & Ground & Translational & 5 \\
Conrod 1 & Crankpin 1 & In-line & 2 \\
Conrod 2 & Crankpin 2 & In-line & 2 \\
Conrod 3 & Crankpin 3 & In-line & 2 \\
Conrod 4 & Crankpin 4 & In-line & 2 \\
Camgear & Ground & Revolute & 5 \\
Journal 3 & Ground & Revolute & 5 \\
Camgear & Journal 3 & Coupler & 1 \\
\hline
\end{tabular}

putation burden and the need for a step-by-step evaluation of contact reaction under elastohydrodynamic conditions (see references [58] and [66]). The connecting rods are connected to the piston by revolute joints, and to their respective crankpins by an in-line joint primitive. The latter introduces two holonomic constraints restricting the lateral movements of the connecting rod with respect to the crankpin. Clearly, axial float of the connecting rod at its big end is inhibited by the revolute joint at the small end. This example serves to illustrate the importance that should be attached to the selection of constraints in a complex multi-body model. If a different joint or a joint primitive had been employed at the big end, restricting the axial float of the connecting rod, a redundant constraint function would have resulted, as this degree of freedom is already constrained by the atpoint (or point coincident) constraints that are implicit in the description of a revolute-type joint.

There are 27 parts in this engine model which are constrained by 65 algebraic constraint functions, thus rendering a 103 degree-of-freedom model when using the Grüebler-Kützbach expression as already highlighted in Section 2.4. To complete the model, provisions have to be made for the following modules:

(a) calculation of combustion forces (see Section 3.2),

(b) determination of crankshaft journal bearing reactions (see Section 3.3),

(c) inclusion of friction torque and piston friction.

\subsection{Calculation of combustion forces}

Cylinder pressure in a power stroke gradually increases as the crankshaft rotates, forcing the piston towards its top dead centre position. At some point in the vicinity of top dead centre (depending on the type of engine), fuel is injected into the cylinder. The rate of rise of pressure is then greatly increased by combustion, resulting in a peak pressure a few degrees (in terms of crank angle) beyond the top dead centre. The pressure is subsequently reduced as the gases expand and the piston travels downwards towards the bottom dead centre. The cylinder pressure can be calculated through application of the first law of thermodynamics to the trapped airfuel mixture. For simplicity, the gas mixture can be 
treated as ideal with air properties. The rate of change in pressure is therefore given as

$$
\frac{\mathrm{d} P}{\mathrm{~d} t}=\frac{\gamma-1}{V}\left(\frac{\mathrm{d} Q}{\mathrm{~d} \tau_{\mathrm{h}}}-\frac{\mathrm{d} Q}{\mathrm{~d} \tau_{\mathrm{t}}}\right)-\frac{\gamma}{V} P \frac{\mathrm{d} V}{\mathrm{~d} t}
$$

where

$$
\frac{\mathrm{d} Q}{\mathrm{~d} \tau_{\mathrm{h}}}=h_{\mathrm{c}} \frac{\mathrm{d}(m \theta)}{\mathrm{d} t} \quad \text { and } \quad \frac{\mathrm{d} Q}{\mathrm{~d} \tau_{\mathrm{t}}}=h_{\mathrm{t}} A_{\mathrm{p}}\left(T_{\mathrm{g}}-T_{\mathrm{w}}\right)
$$

The terms $\mathrm{d} Q / \mathrm{d} \tau_{\mathrm{h}}$ and $\mathrm{d} Q / \mathrm{d} \tau_{\mathrm{t}}$ represent the rate of heat release in the combustion process and the heat transfer rate to the cylinder head and bore walls respectively. The mass fraction of the fuel burnt, $m \theta$, is calculated as a Wiebe function [101] and the instantaneous heat transfer coefficient, $h_{\mathrm{t}}$, can be obtained by Woschini's correlation [102]. The instantaneous piston gas force is calculated by obtaining the gas pressure over the piston crown surface area.

The piston viscous friction force that acts between the piston compression ring and the cylinder wall is formulated in terms of the cylinder pressure in each stroke of the piston. This force can be represented in terms of the crankshaft velocity, $\dot{\phi}_{\mathrm{c}}$, the value of which is instantaneously related to the piston translational velocity, $v_{\mathrm{p}}$. This takes the following typical form:

$$
F_{\mathrm{f}}=\mu A_{\mathrm{p}} \tan ^{-1}\left(\frac{\beta v_{\mathrm{p}}}{\pi / 2}\right) f\left(\dot{\phi}_{\mathrm{c}}\right)
$$

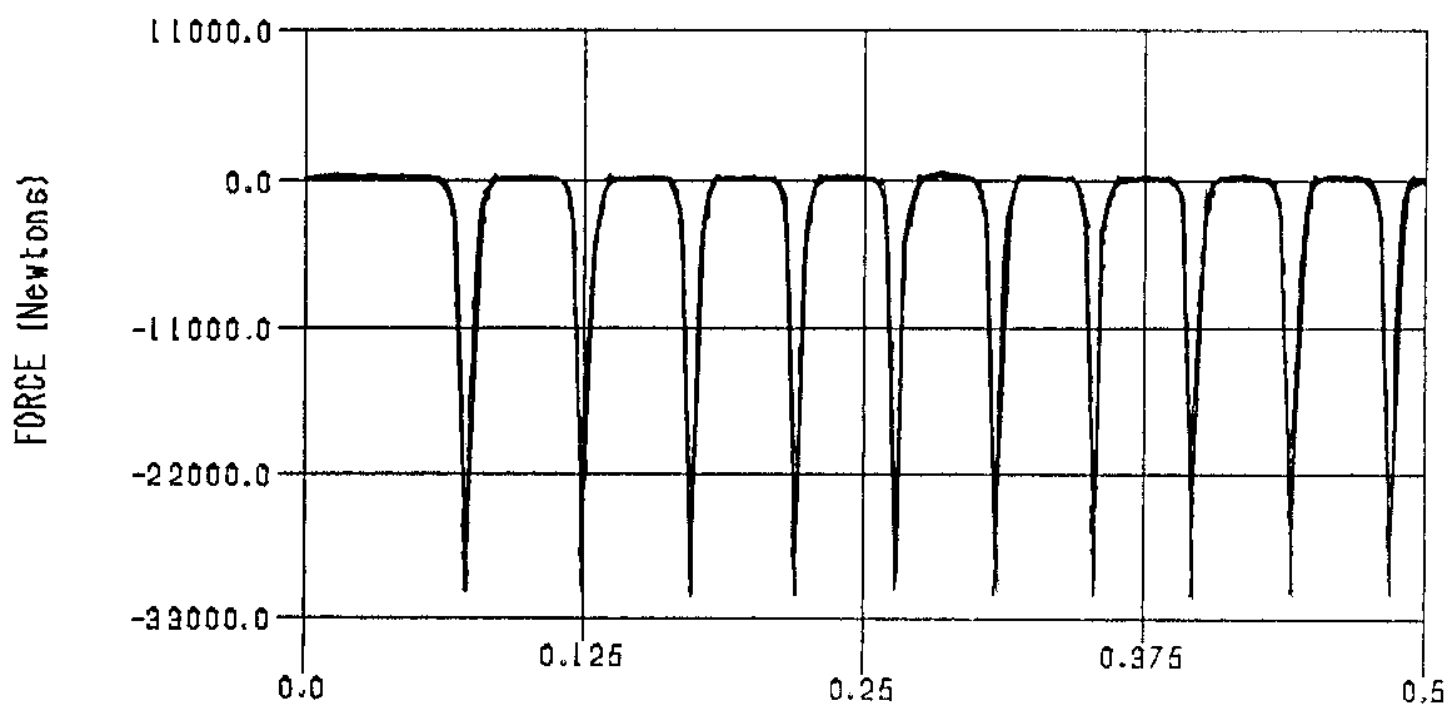

(a)

TIME (sec)

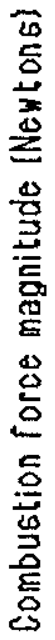

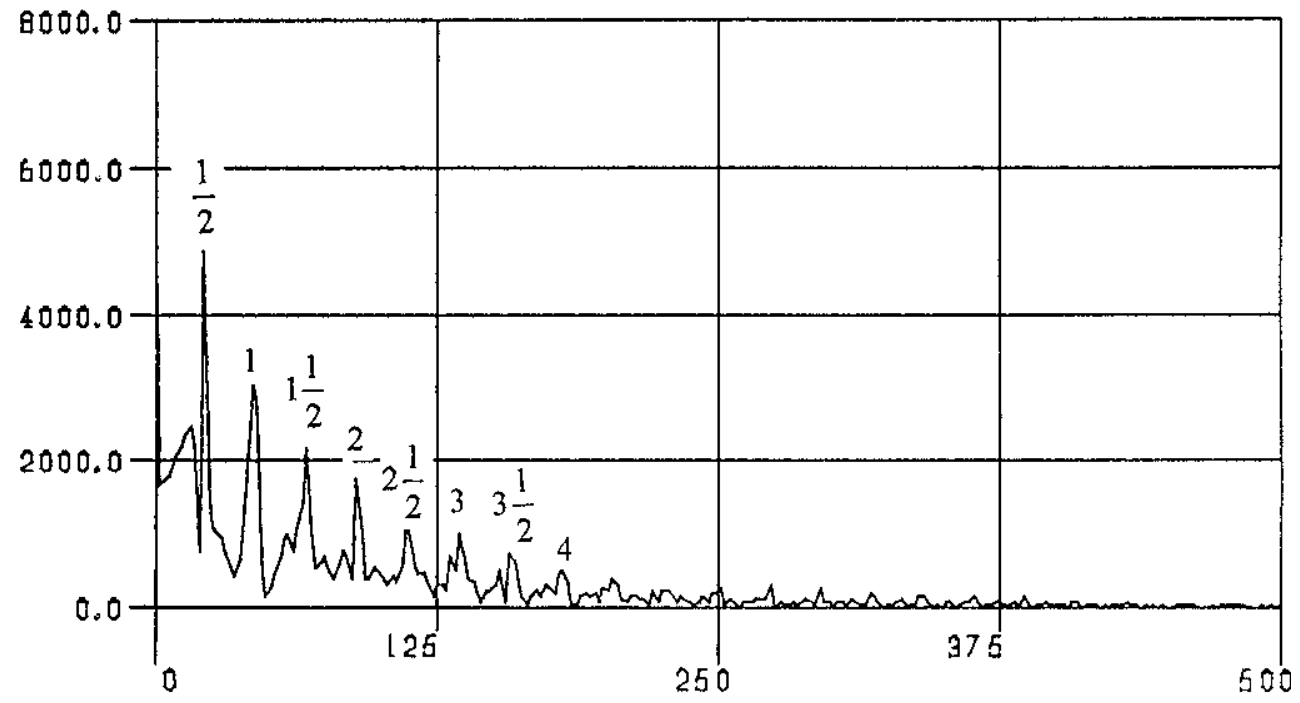

(b)

Frequency $(\mathrm{Hz})$

Fig. 7 (a) Cylinder combustion force time history and (b) combustion force spectral composition 
In a four-cylinder, four-stroke engine there is only one firing pulse per cylinder every two crankshaft revolutions. Therefore, the fundamental firing frequency occurs at half-engine order. A contribution would then be expected at this frequency and all its higher harmonics, these being at all integer multiples of half-engine order. Therefore, the solution to equation (1) yields a maximum pressure for each cylinder once per two revolutions of the crankshaft. Figure 7 a shows the cylinder combustion force variation. Note that the pressure profile initially undergoes a transient condition for a period of $0.1 \mathrm{~s}$. This is due to the simulation conditions from a rest position, when a starter motor is employed to initiate the rotation of the crankshaft, as in a real engine. This starter motor torque overcomes the friction torque to turn the crankshaft before the combustion process commences. Clearly, the very initial oscillations from the rest position follow the crankshaft rotational speed (i.e. with a period corresponding to engine order). As combustion occurs, the remaining cycles follow the four-stroke half-engine order fundamental frequency. The combustion force spectral content is in fact quite complex and, as mentioned above, includes the higher harmonics of the combustion frequency. This can be observed in Fig. 7b, depicting the spectral composition of the combustion force time history of a cylinder.

The situation becomes more complex as the power torque applied to the crankshaft is due to contributions of all cylinders and can be analytically represented as [58]

$$
T=\sum_{j=1}^{n} F_{j k} \mathrm{e}^{i(k / 2)\left(\dot{\phi}_{\mathrm{c}} t-\psi_{j}\right)}
$$

where for a four-cylinder engine $n=4$.

It can be shown that for a four-cylinder, four-stroke engine the summation in equation 3 for no cylinder-tocylinder combustion variation yields non-diminishing even-engine order contributions for the usual cylinder firing order 1-3-4-2 and with the cylinder firing phase shift vector $\left\{\psi_{j}\right\}_{j=1,4}=\{0,3 \pi, \pi, 2 \pi\}^{\mathrm{T}}$, with the second engine order accounting for the main contribution [58]. Note that this in fact coincides with the main contribution of the secondary inertial imbalance at the same frequency for all engine speeds. Therefore, the dominant effect of the second engine order is established. This corroborates the analytical investigations by Rahnejat [58] and the experimental results put forward in references [97] and [98].

Figure $8 \mathrm{a}$ shows the firing order in the four-cylinder engine under investigation. The resultant applied combustion force, being the instantaneous addition of these, is shown in Fig. 8b, with its spectral composition in Fig. $8 \mathrm{c}$. It can be observed that the spectrum of the applied force is dominated by the second engine order and its higher harmonics up to the tenth engine order. This is in fact the 'signature' of a four-cylinder, four-stroke engine - its identifying characteristic. The resulting power torque is applied to the crankshaft and induces torsional vibrations that consist of the same even-order contributions if the crankshaft assembly is rigid and no cylinder-to-cylinder combustion variation is to occur. With modern engines the latter condition is certainly attainable, but the former assumption is not true of any structure, particularly at increasingly high combustion forces acting upon progressively lighter engine constructions. In fact, it can be shown analytically that for an elastic crankshaft the torsional deflection responses occur at half-multiples of engine order as internal sources of excitation [58]. Experimental evidence corroborates this, particularly at $2 \frac{1}{2}$ and $3 \frac{1}{2}$ engine orders for four-cylinder in-line engines.

At this stage of analysis the focus should be on problems that are of interest to practising engine designers. These include the determination of viability of an engine on the basis of, for example, the required starter motor torque to overcome a calculated or a measured friction torque in a crankshaft system configuration or to predict peak bearing loads under dynamic conditions and use this to predict the fatigue life of bearing shells. Another problem, recently exacerbated by the reduction in stiffness of the crank through the increasing use of materials of lighter construction, is the nodding action of the flywheel in combined torsional deflection vibration of the crankshaft and conical whirl of the crankshaft/flywheel assembly, with its apex at the fourth main journal bearing. This motion leads to repetitive impact loading of the drivetrain, with the fourth cylinder firing in the vicinity of its top dead centre, the fundamental frequency of which is at half-engine order and leads to an assortment of drivetrain noise and vibration concerns $[\mathbf{5 9}, \mathbf{6 0}, \mathbf{6 8}-\mathbf{7 3}]$. The nodding motion of the flywheel is determined by the elasticity of the crankshaft, but most prominently by the deflection of the thin shell bearing nearest to the flywheel.

\subsection{Thin shell bearing elastohydrodynamics}

For a four-stroke, four-cylinder engine, the troublesome $2 \frac{1}{2}$ and $3 \frac{1}{2}$ engine orders due to the elastodynamic behaviour of the crankshaft can coincide with its inplane bending modes at around $300-350 \mathrm{~Hz}$ for engine speeds of $4500-6000 \mathrm{r} / \mathrm{min}$ which are within its application speed envelope. At lower speeds, the high vibratory torques can induce failures in the thin shell main support journal bearings of the crankshaft that are increasingly utilized nowadays. The problem is more acute in diesel engines which can produce three times as high a combustion peak pressure than the gasoline engines. Nevertheless, serious problems can still occur with all engine types. Therefore, in this analysis the main 


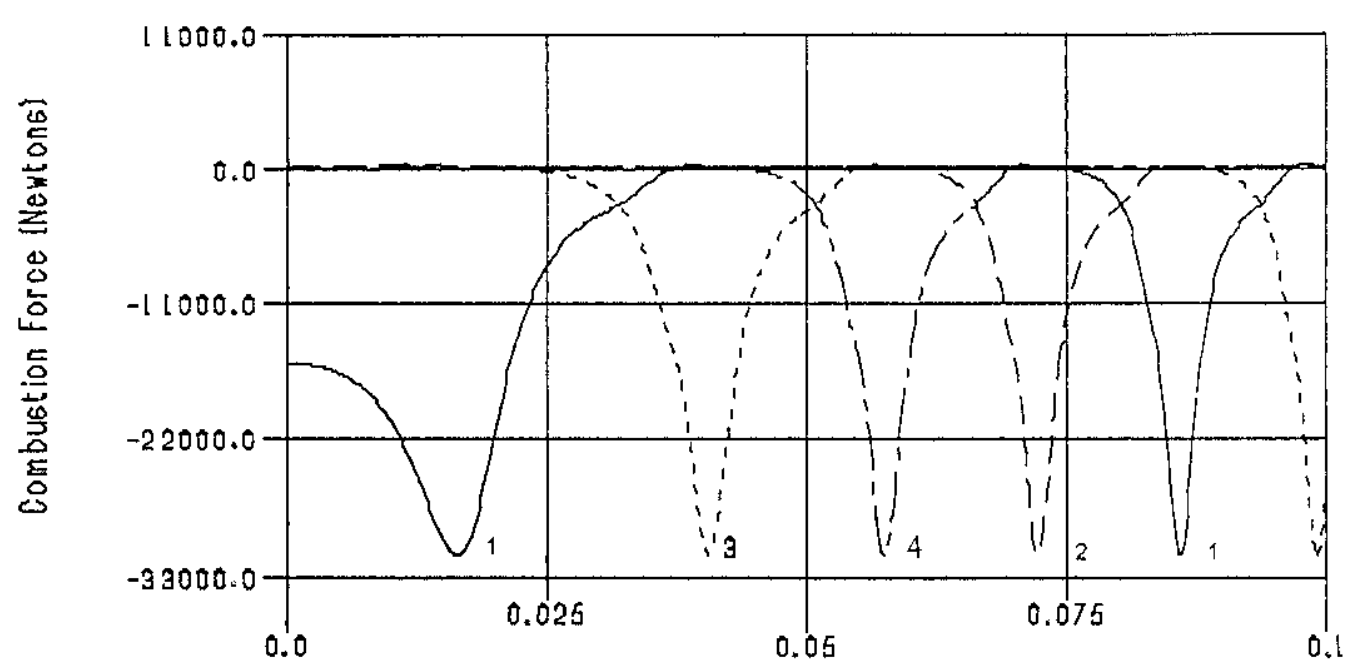

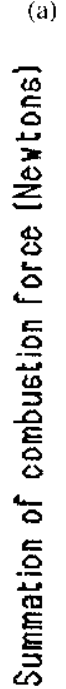

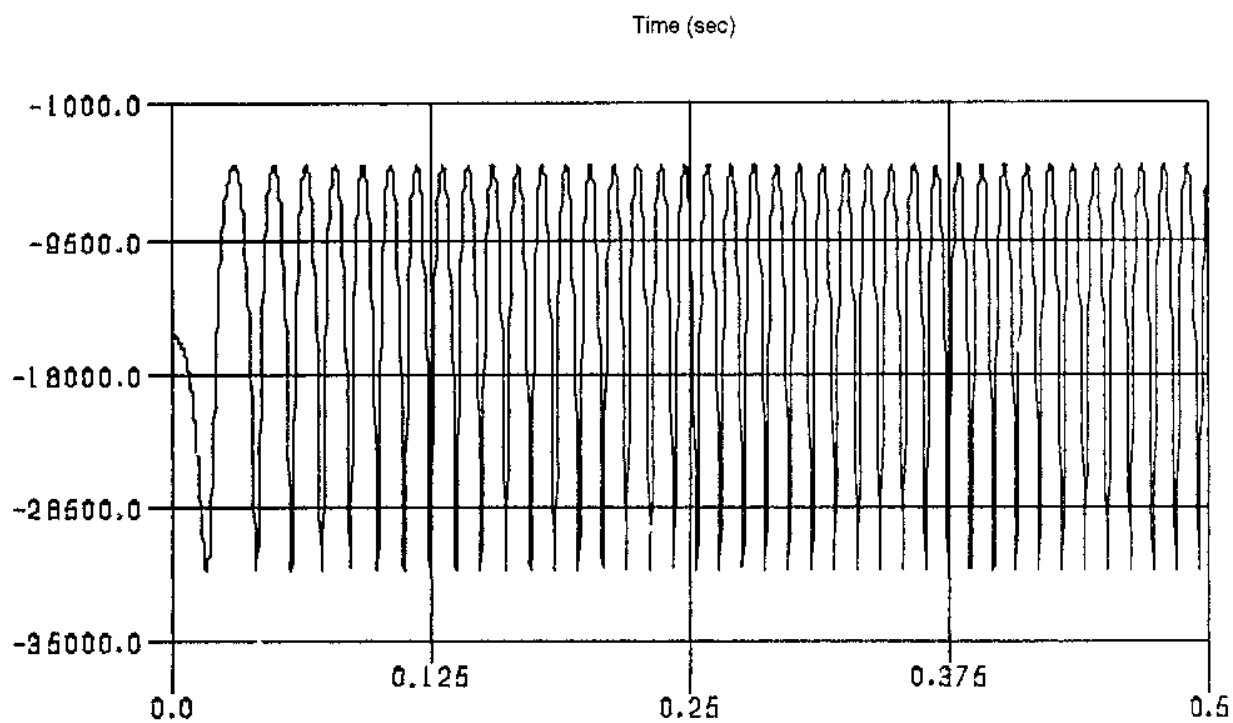

(b)

TIME (sec)

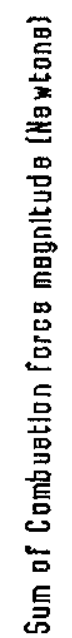

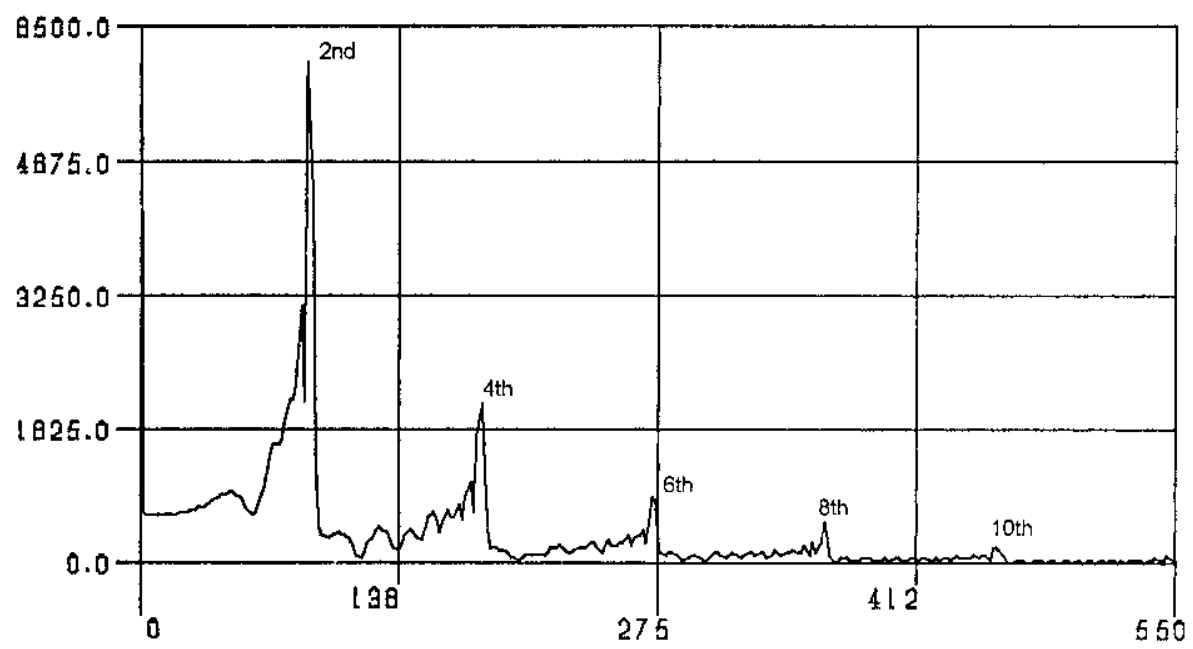

(c)

Frequency $(\mathrm{Hz})$

Fig. 8 (a) Cylinder firing order, (b) combined transient combustion force variation and (c) spectral composition of the applied gas force 
crankshaft journal bearings are modelled as thin shell bearings. The deflection of the thin shell at the bearing nearest to the crankshaft (i.e. the fourth journal) is of particular interest as this induces the nodding action of the flywheel.

The bearings used are thin shell finite-width journal bearings with a $2.5 \mathrm{~mm}$ shell thickness, the shell modulus of elasticity and Poisson's ratio being $60 \mathrm{MPa}$ and 0.33 respectively for the shell made out of Babbit. The radius of the journal is $r=30 \mathrm{~mm}$ and the initial clearance is typically set at $c=r / 1000=30 \mu \mathrm{m}$. The bearing diameter-width ratio is 1.67 , requiring a two- dimensional solution to the Reynolds equation $[\mathbf{1 0}$, 103]:

$$
\frac{\partial}{\partial x}\left(h^{3} \frac{\partial p}{\partial x}\right)+\frac{\partial}{\partial y}\left(h^{3} \frac{\partial p}{\partial y}\right)=12 \eta_{0}\left(u \frac{\partial h}{\partial x}+\frac{\partial h}{\partial t}\right)
$$

For a journal bearing, $x=r \varphi$ and $u=\frac{1}{2} u_{\mathrm{C}}=\frac{1}{2} r \dot{\phi}_{\mathrm{c}}$.

Now, substituting for these in equation (4), the Reynolds equation for a finite-width journal bearing is obtained as

$$
\frac{\partial}{\partial \varphi}\left(h^{3} \frac{\partial p}{\partial \varphi}\right)+r^{2} \frac{\partial}{\partial y}\left(h^{3} \frac{\partial p}{\partial y}\right)=12 \eta_{0}\left(r^{2} \dot{\phi}_{\mathrm{c}} \frac{\partial h}{\partial \varphi}+\frac{\partial h}{\partial t}\right)(5)
$$

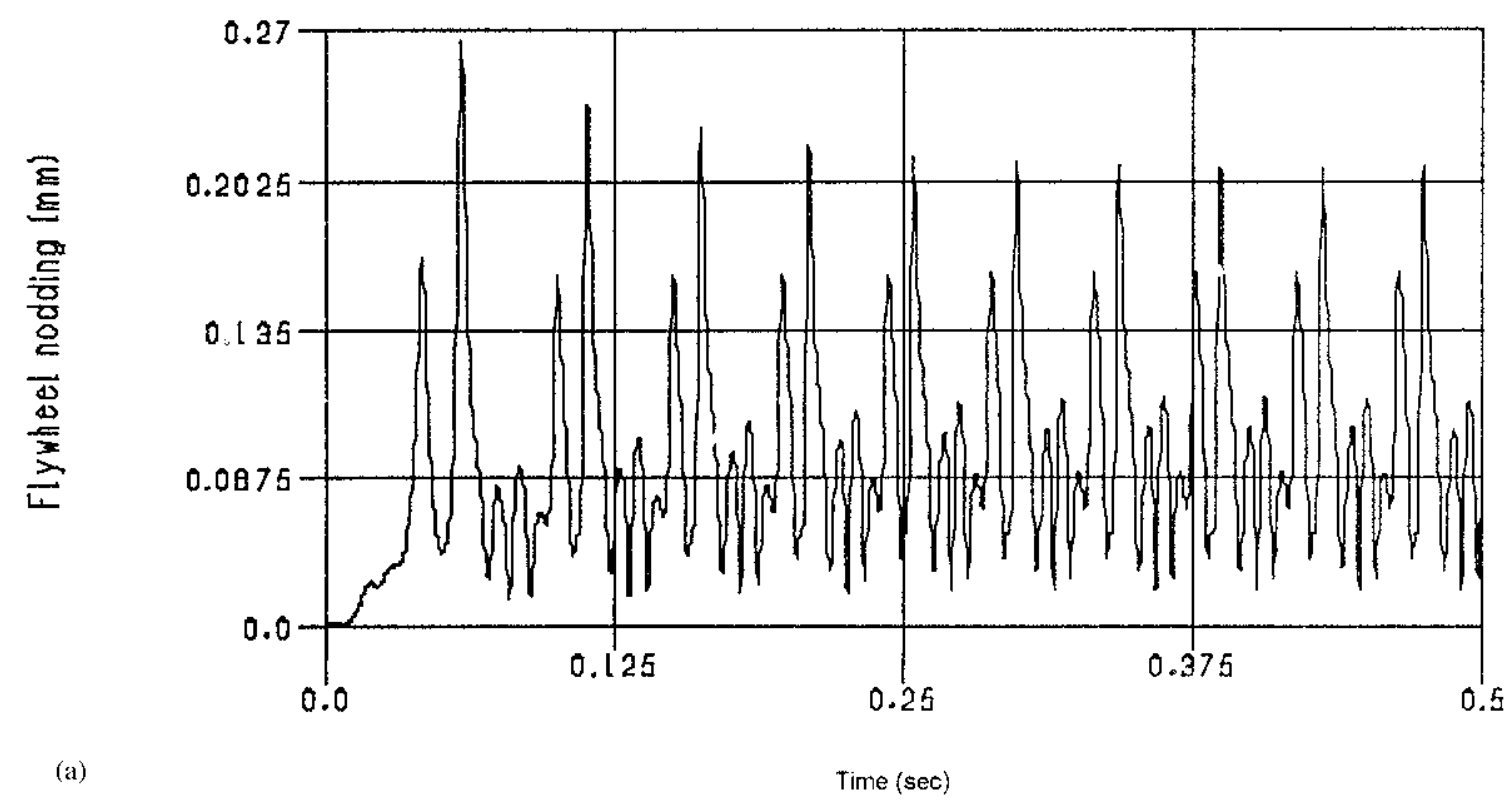

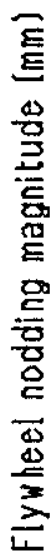

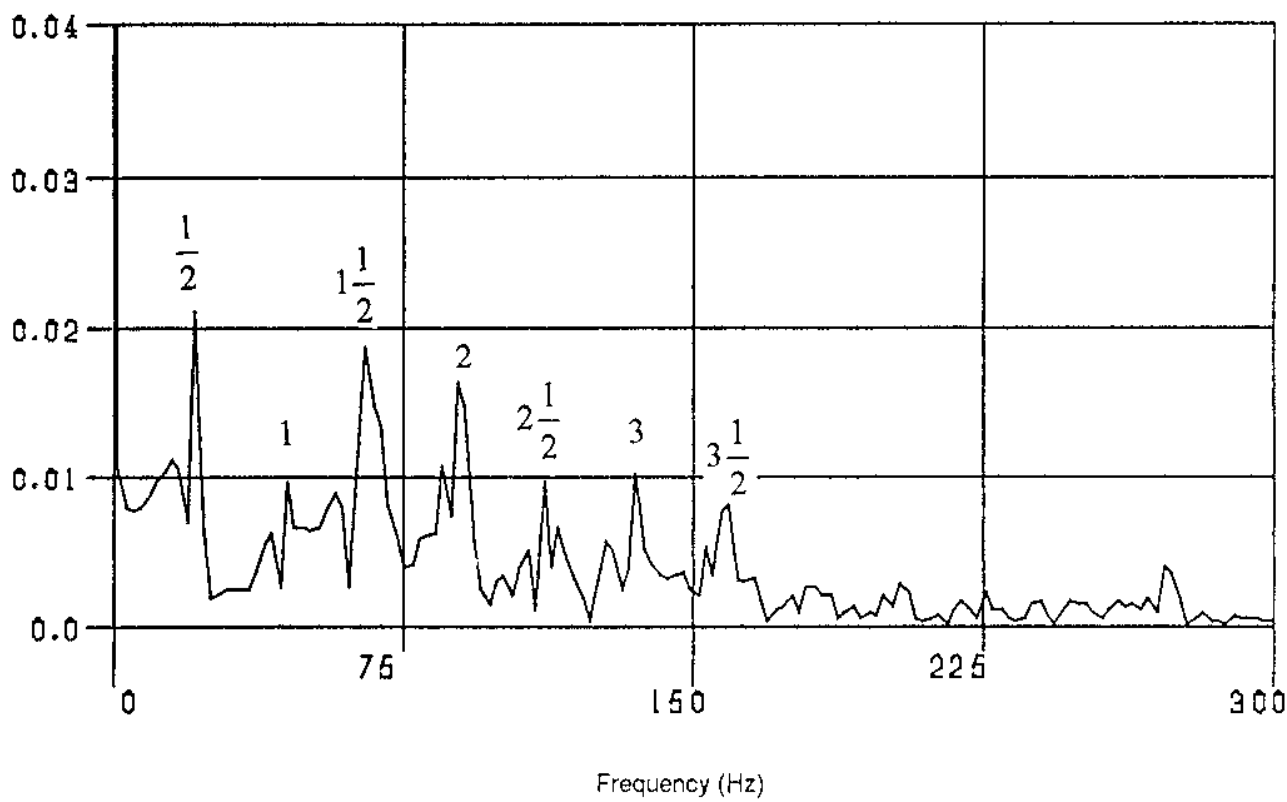

Fig. 9 (a) Time history of flywheel nodding motion and (b) spectrum of flywheel oscillatory motion 
$h(m)$

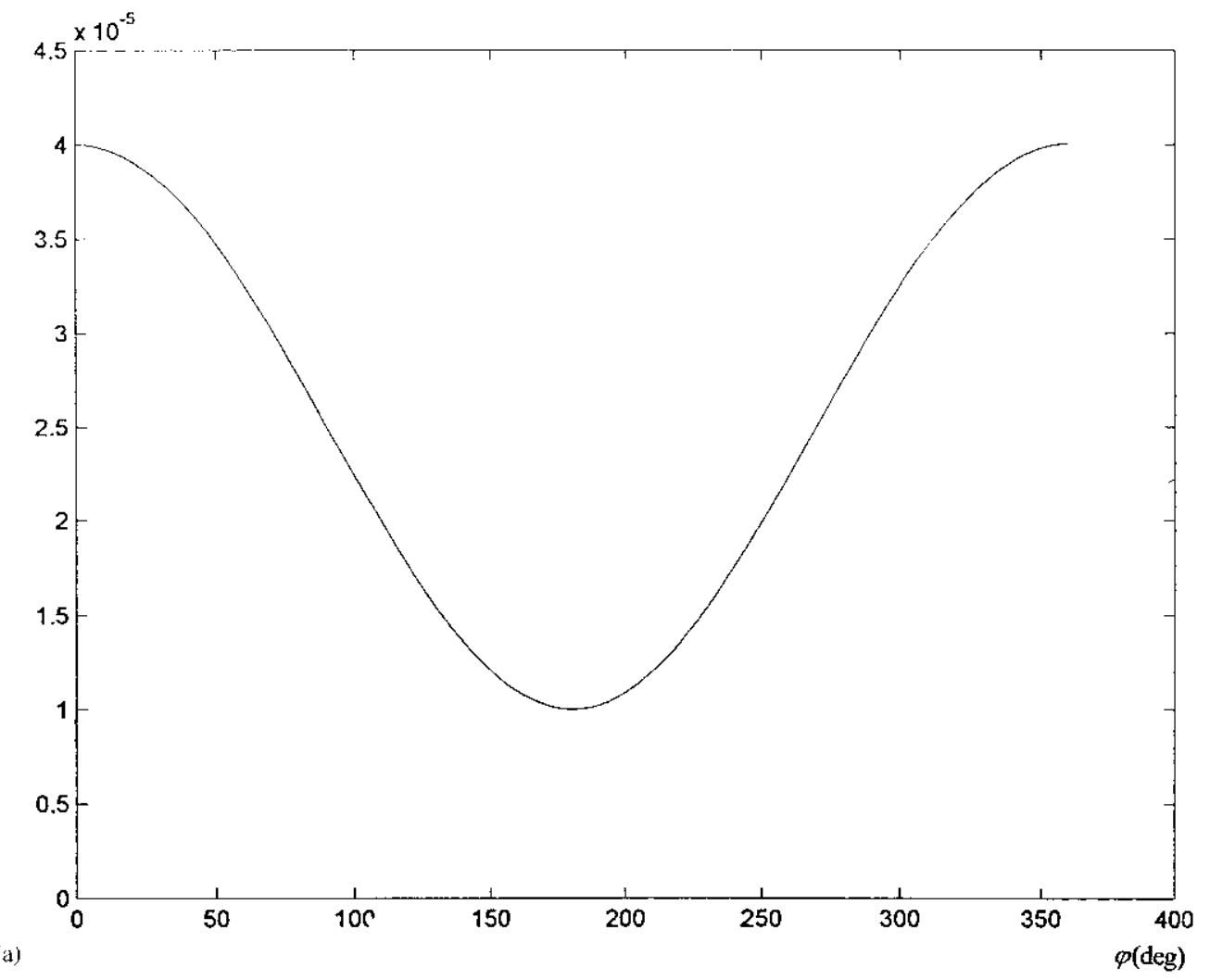

$\mathrm{h}(\mathrm{m})$

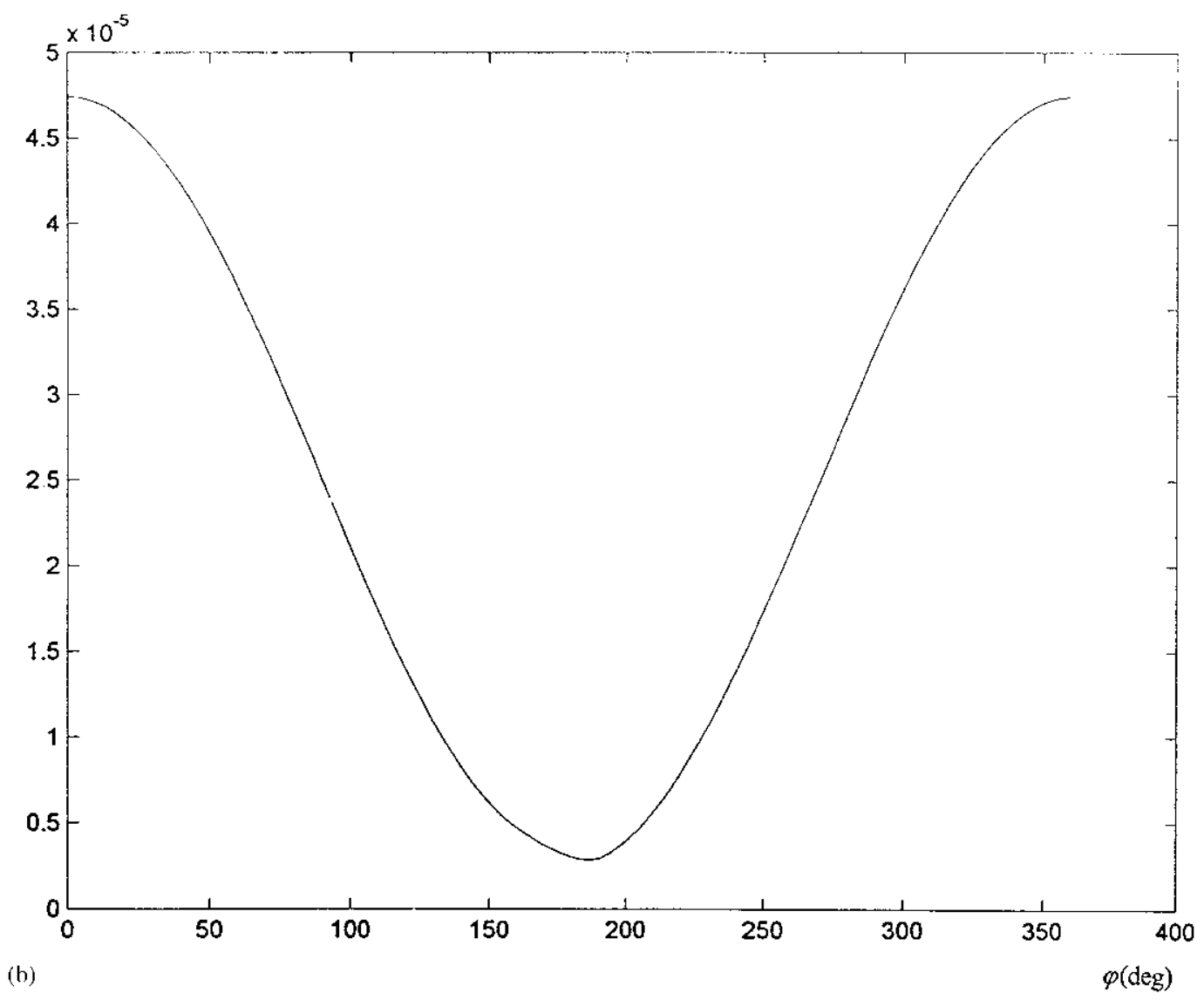

Fig. 10 Central oil-film thickness profiles for bearing loads of (a) $1500 \mathrm{~N}$ and (b) $10000 \mathrm{~N}$ 

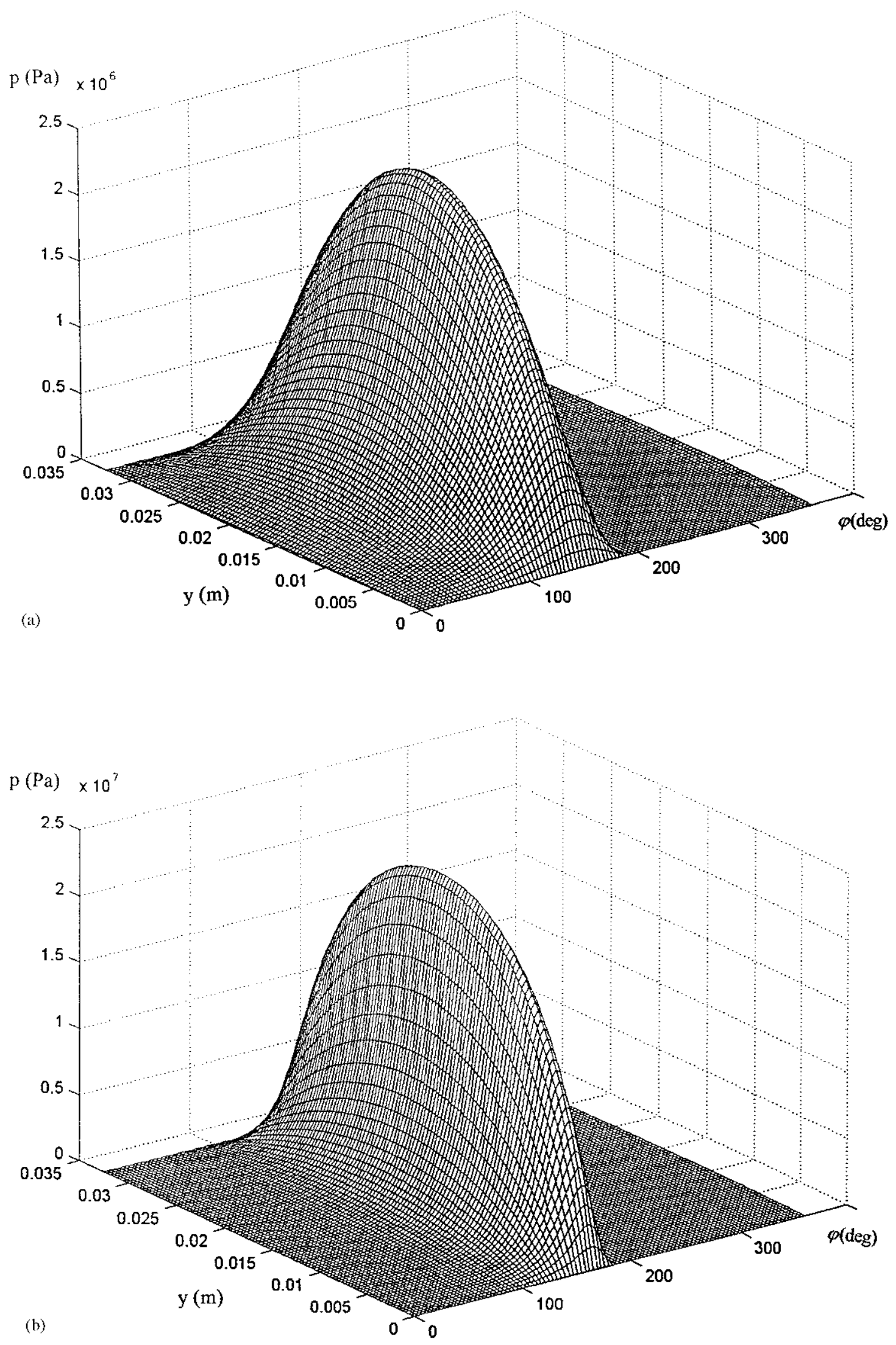

Fig. 11 Three-dimensional pressure distributions for bearing loads of (a) $1500 \mathrm{~N}$ and (b) $10000 \mathrm{~N}$ 
The elastic film shape is given as

$$
h=c(1+\varepsilon \cos \varphi)+\delta
$$

where $\varepsilon=e / c$.

The deflection, $\delta$, at any nodal position within the finite difference mesh (used for the solution of the Reynolds equation) is obtained using the column method. This method determines the deflection in the shell as a result of the elastohydrodynamic pressure element acting directly upon it. In reality, deflection at any location is the result of all pressure elements in the pressure distribution. However, for solids of low elastic modulus, the results from the column method are sufficiently accurate. Thus

$$
\delta=\frac{(1-2 \nu)(1+\nu) d}{E(1-\nu)} p
$$

The Reynolds equation is discretized using finite differences, and a relaxation method is employed in its simultaneous solution with equations (6) and (7), using the Reynolds boundary conditions [10]. The numerical procedure is the same as that described for a hydrodynamic finite-width journal bearing by Hamrock [103].

The elastic deflection of the bearing shell results in the bending of the crankshaft at its supports which manifests itself as the conical whirling motion of the flywheel, referred to as wobble, with its oscillatory component about the horizontal lateral axis termed as the nodding motion of the flywheel. This nodding motion is usually given in terms of the axial displacements of a point on the surface of the flywheel in contact with the friction lining pads on the clutch friction disc (i.e. the mean radius of the friction disc lining). Figure 9a shows the time history of the flywheel nodding. Two important points should be noted. Firstly, the peak amplitude of oscillation is approximately $0.25 \mathrm{~mm}$, which is significant for a gasoline engine but not as high as $0.5-0.7 \mathrm{~mm}$ experienced by some diesel engines (this being an unacceptably high vibratory motion). Secondly, the peak amplitudes occur with fourth cylinder firing (a fact that has been observed experimentally, for example, by Kelly et al. [69]). The spectrum of oscillations is shown in Fig. 9b. The dominant effect of halfengine order is noted, with all its higher harmonics. The main inertial imbalance contribution at second engine order is observed, together with the main contributions due to torsional deflection modes at $1 \frac{1}{2}, 2 \frac{1}{2}$ and $3 \frac{1}{2}$ engine orders, observed under experimental conditions $[\mathbf{5 8}, \mathbf{9 7 -}$ 99].

It is also of practical interest to obtain the oil-film thickness and pressure distribution under various conditions in the fourth journal bearing, nearest to the flywheel. These are clearly calculated in each time step of simulation, as the use of the column method enables their rapid evaluation. Two thousand time steps are employed for the simulation study of the entire model, totalling a computation time of $0.5-1.5 \mathrm{~h}$ on an Indy 5000 SGI workstation.

Figures $10 \mathrm{a}$ and $\mathrm{b}$ show the central oil-film thickness profiles at an engine speed of $1500 \mathrm{r} / \mathrm{min}$ and at journal reactions of 1500 and $10000 \mathrm{~N}$ respectively. Note that the minimum central film thickness has decreased from a value of 12 to $3 \mu \mathrm{m}$ with the increasing bearing load. The corresponding three-dimensional pressure distributions are shown in Figs $11 \mathrm{a}$ and $\mathrm{b}$ respectively. The maximum pressure occurs when the bearing reaction is $10000 \mathrm{~N}$, with a magnitude of $23 \mathrm{MPa}$, this being within the normal operating specification of the bearing.

\section{CONCLUDING REMARKS}

An outline of historical evolution in the field of dynamics has shown that the early investigations and hypotheses in the mechanics of terrestrial motion have resulted in the fundamental understanding of physics of motion in multi-body systems. The improvements in methods of formulation of differential algebraic equations in the eighteenth century and in methods of solution since the late nineteenth century, together with increasing computation power in recent years, have resulted in the analysis of complex machines and mechanisms today.

Practical applications of multi-body dynamics have been discussed. In particular, two major models in two application areas, namely vehicle handling analysis and powertrain dynamics, have been discussed and their practical uses highlighted. It has been shown that inclusion of component flexibility, impact dynamics and tribology in multi-body models represent the growing areas for research and development in the field.

The challenge in the field of multi-body dynamics is to develop efficient solution algorithms in order to be able to obtain the response of systems across a range of lowfrequency rigid body motions to high-frequency noise generated by structural deformation and short-lived transient impact conditions.

In short, it would be true to say of the history of dynamics that it is a science that has come to earth from the heavens. Its ultimate future in the millennium ahead must lie in enabling humanity to take an opposite journey.

\section{ACKNOWLEDGEMENTS}

The author wishes to acknowledge the help of his research staff, Manu Kushwaha, Davud Jalali and Shawky Hegazy, for the preparation of the numerical results presented in this paper. Thanks are also due to his other research students and colleagues from Ford Motor Company, Mike Menday and Patrick Kelly, for 
discussions of various practical aspects highlighted in this paper.

\section{REFERENCES}

1 Galileo, G. Dialogue on the Two Chief World Systems, 1632 (Florence).

2 Galileo, G. Discourses Concerning Two New Sciences, 1638 (Leiden).

3 Kepler, J. Astronomia Nova, 1609 (Graz, Austria).

4 Kepler, J. Harmonice Mundi, 1619 (Graz, Austria).

5 Copernicus, N. De Revolutionibus Orbium Coelestium, 1543 (Nuremburg, Germany).

6 Newton, I. Philosophiae Naturalis Principia Mathematica, 1687 (Royal Society, London).

7 Lagrange, J. L. Mécanique Analytique, 1788 (L'Académie Royal des Sciences, Paris).

8 Euler, L. Nova methods motum corporum rigidarum determinandi. Novi Commentarii Academiae Scientiarum Petropolitanae, 1776, 20, 208-238.

9 Hertz, H. Miscellaneous Papers, 1896 (Macmillan, New York).

10 Reynolds, O. On the theory of lubrication and its application to Mr. Beauchamp Tower's experiments including an experimental determination of the viscosity of olive oil. Phil. Trans., Lond., 1886.

11 Grubin, A. N. Investigation of Scientific and Industrial Research, 1949, Book 30 (Central Scientific Research Institute for Technology and Mechanical Engineering, Moscow).

12 Denavit, J. and Hartenberg, R. S. A kinematic motion for lower pair mechanisms based on matrices. J. Appl. Mech., 1955, 22, 215-221.

13 Gear, C. W. Simultaneous numerical solution of differential-algebraic equations. Circuit Theory, 1971, 18, 89 95.

14 Gear, C. W. The numerical solution of problems which may have high frequency components. In Proceedings of NATO ASI on Computer Aided Analysis and Optimization of Mechanical System Dynamics, 1984 (SpringerVerlag).

15 Petzold, L. R. An efficient numerical method for solving stiff and non-stiff systems of ordinary differential equations. SIAM J. on Numer. Analysis, 1981, 18, 455-479.

16 Ascher, U. and Petzold, L. R. Projected implicit RungeKutta methods for differential-algebraic equations. SIAM J. on Numer. Analysis, 1991, 28, 1097-1120.

17 Gammel, R. Der Kreisel-Seine Theorie und seine Anwendungen, 1st edition, 1920 (Vieweg, Braunschweig); 2nd edition, 1950 (Springer-Verlag, Berlin).

18 Magnus, K. Kreisel-Theorie und Anwendungen, 1971 (Springer-Verlag, Berlin).

19 Wittenbauer, F. Graphische Dynamik, 1923 (SpringerVerlag, Berlin).

20 Fischer, O. Einführung in die Mechanik lebender Mechanismen, 1906 (Leipzig).

21 Segel, L. Theoretical prediction and experimental substantiation of the response of the automobile to steering control, in research in automobile stability and control and in tyre performance. Proc. Instn Mech. Engrs, 1956-7
(7), 310-330.

22 McHenry, R. R. An analysis of the dynamics of automobiles during simultaneous cornering and ride motions, in handling of vehicles under emergency conditions. Proc. Instn Mech. Engrs, 1968-9 (13), 28-48.

23 Orlandea, N., Chace, M. A. and Calahan, D. A. A sparsity-oriented approach to the dynamic analysis and design of mechanical systems, Parts I and II. Trans. ASME, J. Engng for Industry, 1977, 99, 773-784.

24 Levinson, D. A. Equations of motion for multi-rigid-body systems via symbolic manipulation. J. Spacecraft and Rockets, 1977, 14, 479-487.

25 Schiehlen, W. and Kreuzer, E. Rechnergestützus aufstellen der Bewegungsgleichungen gewöhnlicher Mehrkörpersysteme. Ingenieur-Arch., 1977, 46, 185-194.

26 Kortüm, W. and Sharp, R. S. Multi-body Computer Codes in Vehicle System Dynamics, 1973 (Swets und Zeitlinger, Amsterdam).

27 Kortüm, W. and Schiehlen, W. General purpose vehicle system dynamics software based on multi-body formalisms. Veh. Syst. Dynamics, 1985, 14, 229-263.

28 Sharp, R. S. The application of multi-body computer codes to road vehicle dynamics modelling problems. Proc. Instn Mech. Engrs, Part D, Journal of Automobile Engineering, 1994, 208(D1), 63-70.

29 Sharp, R. S. Multi-body dynamics applications in vehicle engineering. In Proceedings of IMechE Conference on Multi-body Dynamics: New Techniques and Applications, London, 1998, paper C553/045/98, pp. 215-228.

30 Schiehlen, W. and Schäfer, P. Modelling of vehicles with controlled components. In Proceedings of 11th Symposium on Dynamics of Vehicles on Roads and on Tracks (Ed. R. J. Anderson), 1989, pp. 488-501 (Swets and Zeitlinger, Amsterdam).

31 Kübler, R. and Schiehlen, W. Vehicle modular simulation in system dynamics. In Proceedings of IMechE Conference on Multi-body Dynamics: New Techniques and Applications, London, 1998, paper C553/039/98, pp. 249 258.

32 Abe, M. Vehicle dynamic and control for improving handling and active safety: from $4 \mathrm{WS}$ to DYC. In Proceedings of IMechE Conference on Multi-body Dynamics: New Techniques and Applications, London, 1998, paper C553/047/98, pp. 229-248.

33 Evans, J. R. Multi-body techniques in railway applications. In Multi-body Dynamics: Monitoring and Simulation Techniques (Eds H. Rahnejat and R. Whalley), 1997, pp. 281-294 (Mechanical Engineering Publications, London).

34 Evans, J. R. and Clementson, J. Application of multibody dynamics to derailment safety. In Proceedings of IMechE Conference on Multi-body Dynamics: New Techniques and Applications, London, 1998, paper C553/014/98, pp. 269-278.

35 Erdman, A. G. and Sandor, G. N. Kineto-elastodynamics: a review of the state of the art and trends. Mechanisms and Mach. Theor., 1972, 7, 19-33.

36 Cavin, R. K. and Dusto, A. R. Hamilton's principle: finite element methods and flexible body dynamics. Am. Inst. Aeronaut. Astronaut. J., 1977, 15, 1684-1690.

37 Changizi, K. and Shabana, A. A. A recursive formulation for the dynamic analysis of open loop deformable multi- 
body systems. Trans. ASME, J. Appl. Mech., 1988, 55, 687-693.

38 Shabana, A. A. Flexible multi-body dynamics: Review of past and present developments. Multi-body Syst. Dynamics, 1997, 1, 189-222.

39 Friberg, O. A method for selecting deformation modes in flexible multi-body dynamics. Int. J. for Numer. Meth. in Engng, 1991, 32, 1637-1656.

40 Avello, A., Urruzola, J., Garcia, J. and Jiménez, J. M. A simple and efficient formulation for the dynamic analysis of flexible multi-body systems. In Multi-body Dynamics: Monitoring and Simulation Techniques (Eds H. Rahnejat and R. Whalley), 1997, pp. 305-314 (Mechanical Engineering Publications, London).

41 Anteun, R. J., Hackett, P. B., O'Leary, M. C. and Sitchin, A. Vehicle dynamic handling computer simulation-model development, correlation and application using ADAMS. In Proceedings of International Congress and Exposition, Detroit, Michigan, February 1986, SAE paper 860574 .

42 O'Heron, P., Nikravesh, P. and Arabyan, A. A multibody model simulating tilt wing conversion. Technical Report CAEL-91-5, Computer Aided Engineering Laboratory, University of Arizona, 1991.

43 Pfeiffer, F. Linearisierte Eigenschwingungen von Treibstoff in Beliebigen Behältern. Z. für Flugwissenschaft, 1968, 16, 188-194.

44 Ranganathan, R., Rakheja, S. and Sankar, S. Influence of liquid load shift on the dynamic response of articulated tank vehicles. Veh. Syst. Dynamics, 1990, 19, 177-200.

45 Rakheja, S., Ranganathan, R. and Sankar, S. Field testing and validation of directional dynamic model of a tank truck. Int. J. Veh. Des., 1992, 13, 251-275.

46 Aini, R., Rahnejat, H. and Gohar, R. A five degrees of freedom analysis of vibrations in precision spindles. Int. J. Mach. Tools, Des. and Mfg, 1990, 30, 1-18.

47 Aini, R., Rahnejat, H. and Gohar, R. An experimental investigation into bearing-induced spindle vibration. Proc. Instn Mech. Engrs, Part C, Journal of Mechanical Engineering Science, 1995, 209(C1), 107-114.

48 Matsubara, M., Rahnejat, H. and Gohar, R. Computational modelling of precision spindles supported by ball bearings. Int. J. Mach. Tools, Des. and Mfg, 1988, 28, 429-442.

49 Gad, E. H., Fukata, S. and Tamura, H. Computer simulation of rotor axial and radial vibrations based on ball bearings. Memoirs Fac. Engng, Kyushu Univ., 1984, 44, 169-189.

50 Gohar, R. and Akturk, N. Vibrations associated with ball bearings. In Proceedings of IMechE Conference on Multi-body Dynamics: New Techniques and Applications, London, 1998, paper C553/044/98, pp. 43-64.

51 Rahnejat, H. and Gohar, R. The vibrations of radial ball bearings. Proc. Instn Mech. Engrs, Part C, Journal of Mechanical Engineering Science, 1985, 199(C3), 181193.

52 Rahnejat, H. Computational modelling of problems in contact dynamics. Engng Analysis, 1985, 2(4); Comput. Mech., 1985, 192-197.

53 Zeischka, J., Mayor, L. S., Schersen, M. and Maessen, F. Multi-body dynamics with deformable bodies applied to flexible rotating crankshaft and engine block. In Pro- ceedings of ASME 94 Fall Technical Conference, Lafayette, October 1994.

54 Katano, H., Iwamoto, A. and Saitoh, T. Dynamic behaviour of internal combustion engine crankshaft under operating conditions. In Proceedings of IMechE Conference, 1991, paper C430/049/91, pp. 205-209.

55 Lacy, D. J. Computers in analysis techniques for reciprocating engine design. In Proceedings of IMechE Conference, 1987, paper C14/87, pp. 55-68.

56 Kikuchi, K. Analysis of unbalance vibration of a rotating shaft system with many bearings and discs. Bull. Jap. Soc. Mech. Engrs, 1970, 13.

57 Boysal, A. and Rahnejat, $\mathbf{H}$. Torsional vibration analysis of a multi-body single cylinder internal combustion engine model. J. Appl. Math. Modelling, 1997, 21, 481493.

58 Rahnejat, H. Multi-body Dynamics: Vehicles, Machines and Mechanisms, July 1998 (Professional Engineering Publishing, Bury St Edmunds, UK and Society of Automotive Engineers, Warrendale, Pennsylvania, USA).

59 Kelly, P. and Rahnejat, H. Clutch pedal dynamic noise and vibration investigation. In Multi-body Dynamics: Monitoring and Simulation Techniques (Eds H. Rahnejat and R. Whalley), 1997, pp. 23-31 (Mechanical Engineering Publications, London).

60 Rahnejat, H., Centea, D. and Kelly, P. Non-linear multibody dynamic analysis for the study of in-cycle vibrations (whoop) of cable operated clutch systems. In Proceedings of 30th International Symposium on Technology and Automation (ISATA), Florence, 1997, paper 97VR010, pp. 243-252.

61 Biermann, J. W. and Hagerodt, B. Investigation of clonk phenomenon in vehicle transmission-measurement, modelling, and simulation. In Multi-body Dynamics: Monitoring and Simulation Techniques (Eds H. Rahnejat and R. Whalley), 1997, pp. 33-45 (Mechanical Engineering Publications, London).

62 Boysal, A. and Rahnejat, H. ADAMS generic engine: a tribo-dynamic analysis tool. In Proceedings of ADAMS International User's Conference 96 on Multi-body Dynamics, Yipsilanti, USA, May 1996, pp. 1-19.

63 Okamura, H., Sogabe, K. and Shinno, A. Dynamic stiffness matrix method for three-dimensional analysis of crankshaft vibrations. In Proceedings of IMechE Conference on Advances in the Control and Refinement of Vehicle Noise, 1988, paper C23/88, pp. 95-108.

64 Okamura, H., Shinno, A., Yamanaka, T., Suzuki, A. and Sogabe, K. Simple modelling and analysis for crankshaft vibrations, Part 1-background and application to free vibrations. Trans. ASME, J. Vibr. and Acoust., 1995, 117, 70-79.

65 Okamura, H. and Morita, T. Simple modelling and analysis for crankshaft three-dimensional vibrations under firing conditions. In Proceedings of IMechE Conference on Multi-body Dynamics: New Techniques and Applications, London, 1998, paper C553/037/98, pp. 9-25.

66 Knoll, G. D. and Peeken, H. J. Hydrodynamic lubrication of piston skirts. Trans. ASME, J. Lubrication Technol., 1982, 104, 504-509.

67 Kryniski, K. Jumping phenomenon in journal bearings. 
Trans. ASME, J. Rotating Mach. and Veh. Dynamics, 1991, 35, 169-173.

68 Kelly, P., Rahnejat, H., Biermann, J. W. and Hagerodt, B. Combining design of experiments and modelling techniques to resolve complex clutch pedal noise and vibration issues. In Proceedings of IMechE Conference on European Vehicle Noise and Vibration, 1998, pp. 297309.

69 Kelly, P., Rahnejat, H. and Biermann, J. W. Multi-body dynamics investigation of clutch pedal in-cycle vibration (whoop). In Proceedings of IMechE Conference on Multi-body Dynamics: New Techniques and Applications, London, 1998, paper C553/013/98, pp. 167-178.

70 Krenz, R. Vehicle response to throttle tip in/tip out. SAE paper 850967, 1985.

71 Arrundale, D., Hussain, K., Rahnejat, H. and Menday, M. T. Acoustic response of driveline pieces under impacting loads (clonk). In Proceedings of 31st International Symposium on Automotive Technology and Automation (ISATA), Düsseldorf, 1998, paper 98SAF029, pp. 319327.

72 Powell, N. N. and March, J. P. Practical applications of dynamic system modelling in powertrain and vehicle refinement. In Multi-body Dynamics: Monitoring and Simulation Techniques (Eds H. Rahnejat and R. Whalley), 1997, pp. 47-57 (Mechanical Engineering Publications, London).

73 Campbell, C. Automotive Suspensions, 1981 (Chapman and Hall, London).

74 Gillespie, T. D. Fundamentals of Vehicle Dynamics, 1992 (Society of Automotive Engineers, Warrendale, Pennsylvania).

75 Bastow, D. and Howard, P. G. Car Suspension and Handling, 3rd edition, 1993 (Pentech Press, London).

76 Sharp, R. S. Variable geometry active suspension for cars. Comput. and Control Engng J., IEE, October 1998, 217-222.

77 El-Beheiry, E. M., Karnopp, D., El Araby, M. E. and Abdelraaouf, A. Advance ground vehicle suspension systems - a classified bibliography. Veh. Syst. Dynamics, 1995, 24, 231-258.

78 Sharp, R. S. and Crolla, D. A. Road vehicle suspension design-a review. Veh. Syst. Dynamics, 1987, 16, 167192.

79 Riede, P. M., Effert, R. L. and Cobb, W. A. Typical vehicle parameters for dynamic studies. SAE paper 840561, 1984.

80 Bakker, E., Nyborg, L. and Pacejka, H. B. Tyre modelling for use in vehicle dynamics studies. SAE paper 870421, 1987.

81 Fonda, A. G. Tyre tests and interpretation of experimental data. Proc. Instn Mech. Engrs, 1956-7, 7, 348366

82 Nordeen, D. K. and Cortese, A. D. Force and moment characteristics of rolling tyres. SAE paper 713A, 1963.

83 Pacejka, H. B. The tyre as a vehicle component. In Proceedings of 26th FISITA Congress, Prague, June 1996, pp. 1-19.

84 Pacejka H. B. and Bakker, E. The magic formula tire model. Veh. Syst. Dynamics, 1993, 21, 1-18.

85 Pacejka, H. B. and Sharp, R. S. Shear force development by pneumatic tyres in steady state condition: A review of modelling aspects. Veh. Syst. Dynamics, 1991, 20, 121176.

86 Pacejka, H. B. Simplified analysis of steady state turning behaviour of motor vehicles, Part 1: Handling diagram of simple system. Veh. Syst. Dynamics, 1973, 2.

87 Pacejka, H. B. Simplified analysis of steady state turning behaviour of motor vehicles, Part 2: Stability of the steady state turn. Veh. Syst. Dynamics, 1973, 2.

88 Giannopoulos, F. and Rao, A. K. Dynamic loads on suspension components using mechanism program. SAE paper 811307, 1981, pp. 63-73.

89 Naude, F. A. and Steyn, J. L. Objective evaluation of the simulated handling characteristics. SAE paper 930826 , 1993, pp. 97-102.

90 Xia, X. and Willis, J. N. The effect of tire cornering stiffness on vehicle linear handling performance. SAE paper 950313,1995 , pp. 117-126.

91 Zegelaar, P. W. A., Gong, S. and Pacejka, H. B. Tire models for the study of in-plane dynamics. Veh. Syst. Dynamics, 1994, 23, 578-590.

92 Vedamuthu, S. and Law, E. H. An investigation of the pulse steer method for determining automobile handling qualities. SAE paper 930829, 1993, pp. 133-161.

93 Levitt, J. A. and Zorka, N. G. The influence of tire damping in quarter active suspension models. Trans. ASME, J. Dynamic Syst., Measmt and Control, 1991, 113.

94 Anderson, R. J. Multi-body dynamics analysis of the ride quality of an off-road articulated truck. In Proceedings of IMechE Conference on Multi-body Dynamics: New Techniques and Applications, London, 1998, paper C553/037/98, pp. 259-268.

95 Blundell, M. V. Full vehicle modelling and simulation using the ADAMS software system. In Proceedings of 16th IMechE Seminar on Simulation of Vehicle Dynamics, 1991, paper C427/16/170

96 Hegazy, S., Rahnejat, H. and Hussain, K. Multi-body dynamics in full-vehicle handling analysis. Proc. Insth Mech. Engrs, Part K, Journal of Multibody Dynamics (submitted for publication).

97 Dixon, J., Rhodes, D. M. and Phillips, A. V. The generation of engine half orders by structural deformation. In Proceedings of IMechE Conference on Vehicle NVH and Refinement, 1994, paper C487/032/94, pp. 9-17.

98 Kinoshita, M., Sakamoto, T. and Okamura, H. An experimental study of a torsional/bending damper pulley for an engine crankshaft. SAE paper 891127, 1989, pp. 23-33.

99 Nakada, T. and Tonosaki, H. Excitation mechanism of half order engine vibrations. In Proceedings of IMechE Conference, 1994, paper C487/017/94, pp. 1-7.

100 March, J. P. and Croker, M. D. Present and future perspectives of powertrain refinement. In Proceedings of IMechE European Conference on Vehicle Noise and Vibration, London, 1998, paper C521/023/98, pp. 23-40.

101 Wiebe, H. Brenverhauf und Kreisproze von Verbrennungsmotoren (Verlag Teknik).

102 Woschini, G. A. A universally applicable equation for the instantaneous heat transfer coefficient in the internal combustion engine. SAE paper 850967, 1985.

103 Hamrock, B. J. Fundamentals of Fluid Film Lubrication, 1994 (McGraw-Hill). 